\title{
Remote Control of Near Infrared Emission with Lanthanide Complexes.
}

\author{
Lucie Norel, ${ }^{\star[a]}$ Olivier Galangau, ${ }^{[a]}$ Hassan Al Sabea, ${ }^{[a]}$ Stéphane Rigaut ${ }^{\star[a]}$
}

[a] Dr. L. Norel, Dr. O. Galangau, Dr. H. Al Sabea, Prof. S. Rigaut

Univ Rennes, CNRS, ISCR (Institut des Sciences Chimiques de Rennes)-UMR 6226, F-35000 Rennes, France

E-mail: stephane.rigaut@univ-rennes1.fr, lucie.norel@univ-rennes1.fr.

\begin{abstract}
Molecular luminescent switches form a unique and fascinating class of compounds which luminescence response can be toggled with chemical or physical stimuli. Switchable Near InfraRed (NIR) emitters are of major interest since they are compatible with in vivo imaging and have potential for advanced materials such as security tags. Of particular interest are the NIR emitting lanthanides, which feature narrow, sharp and intense emission lines originating from the $f$ - $f$ Laporte forbidden transitions. Although, these "fingerprints" are in general rather insensitive to surrounding media, they can be manipulated thanks to a proper engineering of the complex $1^{\text {st }}$ or $2^{\text {nd }}$ coordination spheres. The resulting switching systems may thus find usefulness in various application fields. In this review, we selected representative example of switchable lanthanide NIR emitters based on the most relevant stimuli, such as a chemical, environmental, thermal, electrochemical and photochemical inputs.
\end{abstract}

\section{Introduction}

Molecular switches in which a key property can be modulated with chemical or physical external stimuli are fascinating research objects having relevance in very fundamental questions, inter alia the process of vision, the design of molecular machines, as well as in the development of a variety of applications such as photochromic lenses, smart indicators or sensors and so on. ${ }^{[1]}$ Among them, luminescent switches are particularly attractive to achieve highly sensitive chemical sensors, smart materials as electrofluorochromic displays, ${ }^{[2]}$ local temperature probes, ${ }^{[3]}$ or high resolution cell imaging tools. ${ }^{[4]}$

In the field of fluorescent materials, more and more attention is devoted to emitters in the near infrared (NIR) region, for several reasons. ${ }^{[5]} \mathrm{A}$ major one is the high transparency of biological tissues in the range $650-950 \mathrm{~nm}$ and $1000-1350 \mathrm{~nm}^{[6]}$ that renders in vivo sensing and imaging more accessible with biocompatible NIR emissive probes. ${ }^{[5 c, 7]}$ In the field of material science, focusing on NIR photoluminescence can lead to reduced energy consumption and better photostability of the materials since the photoexcitation energy can be reduced together with the emission one. It also lead to a specific signature, difficult or impossible to detect with the naked eye to avoid visible interferences or to use as security tags. In this context, we can foresee the importance of NIR emission remote control in molecular systems. ${ }^{[8]}$ The switching process could be used for easier in vivo monitoring of changes in $\mathrm{pH}$, redox status, ${ }^{[9]}$ ions concentration or for better resolution imaging in the case of photoswitches. ${ }^{[10]}$ Also, the possibility to switch NIR emitters reversibly can provide security tag with more advanced encryption methods.

Among all fluorophores, lanthanide ions, including NIR emitters $(\mathrm{Nd}(\mathrm{III}), \mathrm{Yb}(\mathrm{III})$ or $\mathrm{Er}(\mathrm{III}))$, occupy a very particular place due to their unique photophysical properties. ${ }^{[11],[12]}$ Indeed, since the emission origins from the Laporte forbidden $f$-f transitions, lanthanide complexes display long lived excited states, narrow bandwidth emission bands and large (pseudo)-Stokes shifts that confer them several advantages compared to other fluorophores, providing they display kinetic stability. ${ }^{[13]}$ First, their narrow bandwidth emission, which detailed structure originates from the crystal field, ${ }^{[14]}$ remains the same in different solvents / media and this "fingerprint" is easily distinguished in signaling tools with sensitive detection, including in vivo. ${ }^{[15]}$ Many markers are now made of lanthanide blends with specific emissions and colors as security labels due to these unique signatures. ${ }^{[16]}$ Note that this fingerprint can however be "manipulated" in a subtle way, by changing the temperature or the metal center environment, thus leading to ratiometric temperature probe or chemical sensors (vide infra). This behavior strongly contrasts with that of low band gap organic compounds displaying broad and featureless emission and prone to aggregation due to their planar structure often leading to quenching. ${ }^{[5 a]}$ The long lifetimes of lanthanide ions also enable time-gated and time-resolved fluorescence lifetime measurements, which can facilitate the discrimination from other emission sources. ${ }^{[11 c]}$ Finally, by engineering both sensitization efficiency and non-radiative vs radiative processes competition, it is actually possible to design NIR emitting lanthanide complexes with exceptional emission quantum yields, ${ }^{[17]}$ that escape the low band gap law.

For all these reasons, our group and others became very interested in the design of lanthanide complexes with controllable NIR emission expecting that the specificities of lanthanide based emission can reinforce the advantages offered by a dynamic emission response in the fields of bio imaging and smart materials. ${ }^{[18]}$ With this prospect, lanthanide complexes have another great advantage: the complexity of their emission mechanism. The mechanism behind emission of lanthanide complexes usually relies on absorption by an antenna, (several types of) transfer(s) between the antenna excited states to reach the lanthanide excited state, and emission in competition with several non-radiative processes. Therefore, the molecular chemists possess several handles to control the emission response by the use of a given stimulus affecting any of the above-mentioned steps as summarized in Figure 1. More specifically, any external stimulus able to: (i) modify the electronic properties of the antenna or its proximity to the emissive center, (ii) modify the metal coordination sphere symmetry or composition including the presence of deleterious vibrators as ligands, (iii) induce an additional quenching mechanism (low lying energy state, oxygen presence), or (iv) change the rate of certain energy transfer(s) can therefore significantly alter the emission spectrum. ${ }^{[19]}$ 
In the present review, we selected from the literature representative examples of NIR emission control based on the most relevant stimuli. As we will detail in the following sections, the introduction of a chemical species in the medium, a change of solvent properties, a temperature variation, a redox process or light irradiation can trigger the process.
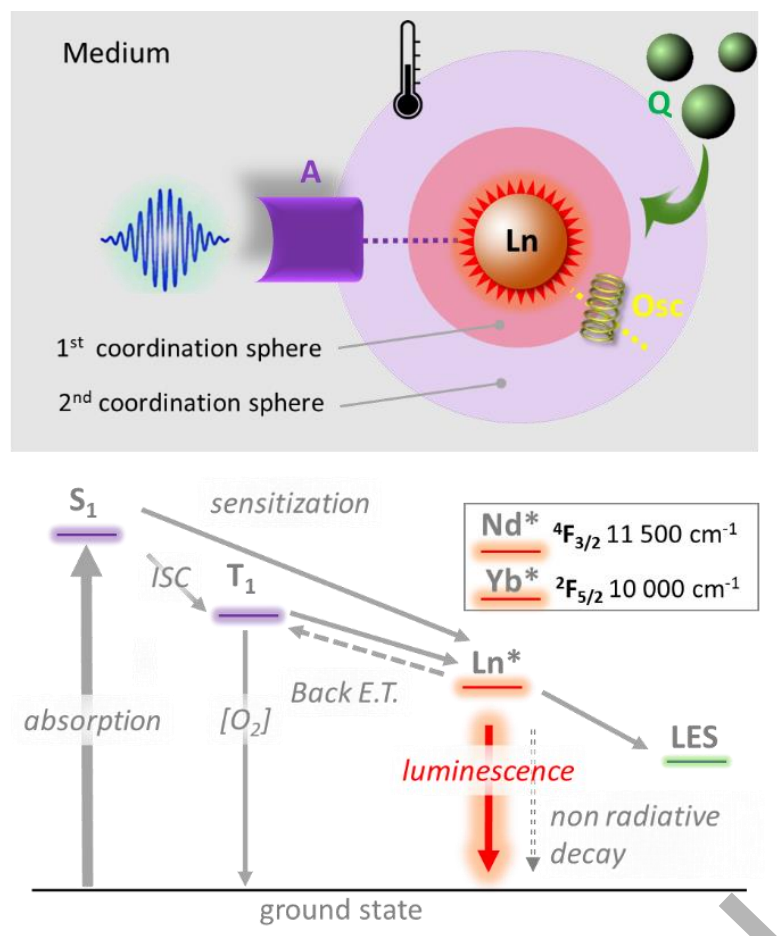

Figure 1. Schematic illustration of the important components of a lanthanidebased emissive complex: the antenna $(A)$ absorbs the photon energy, usually by a $S_{0}-S_{n}$ transition and transfers it to the $f$-f excited state centered on the lanthanide. The emission can be hampered by collision with a quencher $(\mathrm{Q})$ or deactivation by multiphonon non-radiative process upon coupling with a highenergy oscillator (Osc, typically $\mathrm{X}-\mathrm{H}$ vibrations). On the lower panel, a simplified Jablonski diagram shows the corresponding energy levels and important processes that also compete with emission : back energy transfer to the antenna (or other ligand) triplet state, collisional quenching between the triplet state and dioxygen, energy transfer to a low lying energy state (LES).

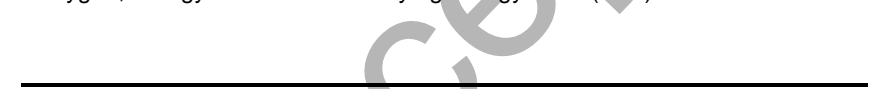

Lucie Norel received her Ph.D. from the University Pierre et Marie Curie in 2008, under the supervision of Prof. Cyrille Train and Dr. Yves Journaux. Following her postdoctoral training with $\mathrm{Dr}$. Jeanne Crassous at University of Rennes 1 (UR1), she joined UR1 in 2009 as Assistant Professor. Her research interests are focused on molecular materials based on lanthanide coordination complexes for luminescence and magnetism.
Olivier Galangau obtained his $\mathrm{PhD}$ in chemistry in 2011 from École Normale Supérieur de Cachan, under the supervision of Prof. P. Audebert. Following his postdoctoral training with Prof. T. Kawai at NAIST (Japan), he moved to Institut des Sciences Chimiques de Rennes (France) working with Dr. F. Pointillart. Since October 2018, he joined the group of Prof. S. Rigaut as CNRS research fellow. He is interested in developing new type of smart molecular/supramolecular materials, combining light- and/or electroswitchability.

Hassan Al Sabea received his B.S. form the Lebanese University faculty of sciences followed by a Master degree in Catalysis, Molecular, \& Green Chemistry in 2017 from University of Rennes 1. He obtained his PhD degree in 2020 from University of Rennes 1, under the supervision of Prof. S. Rigaut and Dr. L. Norel. His topic was dealing with the redox and photo-modulation of lanthanide-based luminescence, as well as the synthesis of molecular wires.

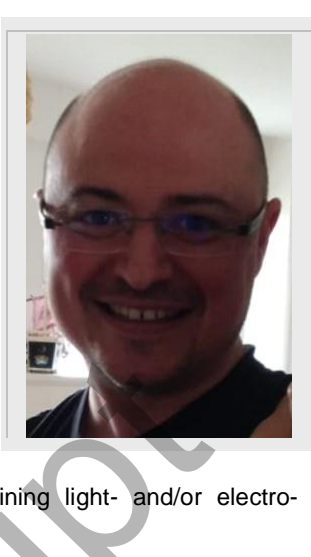

Stéphane Rigaut receieved his Ph.D. from the University Bordeaux 1 in 1997, under the supervision of Prof. Didier Astruc and Dr. Marie hélène Delville. Following a postdoctoral training with Larry Miller at the University of Minnesota, he joined the universty of Rennes 1 in 1998 as an Assistant Professor and was promoted Full Professor in 2008. His research interests are focused toward metal complexes complexes for fonnctionnal molecular materials, including molecular electronics.

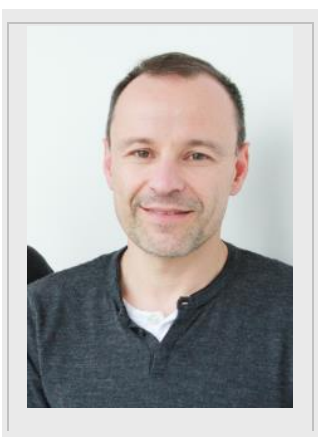

\section{Chemical switching}

Lanthanide complexes with a luminescent response tuned by an interaction with a specific chemical species have been widely developed with visible emitters ${ }^{[19 a, 20]}$ to achieve sensors, but they are less common in the case of NIR emitters as recently reviewed for bio sensing. ${ }^{[5 c]}[21]$

Among others chemicals and as a characteristic switching example, the simplest analyte, but with tremendous importance is proton. In 2012, near-infrared emitting ytterbium-functionalized gold nanoparticles were synthesized by self-assembly at the gold surface between a cyclen complex and xylenol orange. Visible light excitation of the latter unit results in the sensitization of the $\mathrm{Yb}$ (III) centered emission that can be reversibly switched on and off as a function of the $\mathrm{pH}$ value. ${ }^{[22]}$ Another $\mathrm{pH}$ responsive 
molecular system was published in 2014 by Tropiano et al. ${ }^{[23]}$ It relies on the $\alpha$-deprotonation of a ketone ligand to produce a coordinated enolate anion in basic media (Figure 2). Interestingly, the acid-base equilibrium lead to a change in the emission profile, without significant intensity change, directly related to modification of the coordination sphere and hence of the crystal field (CF) splitting. This is in contrast with the corresponding europium complex, where only the ketone form is emissive. In the porphirinate ytterbium complex developed by $\mathrm{Li}$, Zhang et al (Figure 3), ${ }^{[24]}$ the mechanism and outcome are very different since deprotonation produces uncoordinated carboxylate groups involved as good donors in a photoinduced electron transfer (PET) that quenches the emission, and is suppressed in acidic conditions. In that case, emission is more intense at $\mathrm{pH}$ lower than 6 with a 7 -fold intensity increase at acidic $\mathrm{pH}$ along with a change in lifetime from 13.4 to $135 \mu$ s. Together with aggregation at very low $\mathrm{pH}$, this allows in vivo imaging of gastrointestinal $\mathrm{pH}$ based on real time lifetime detection.

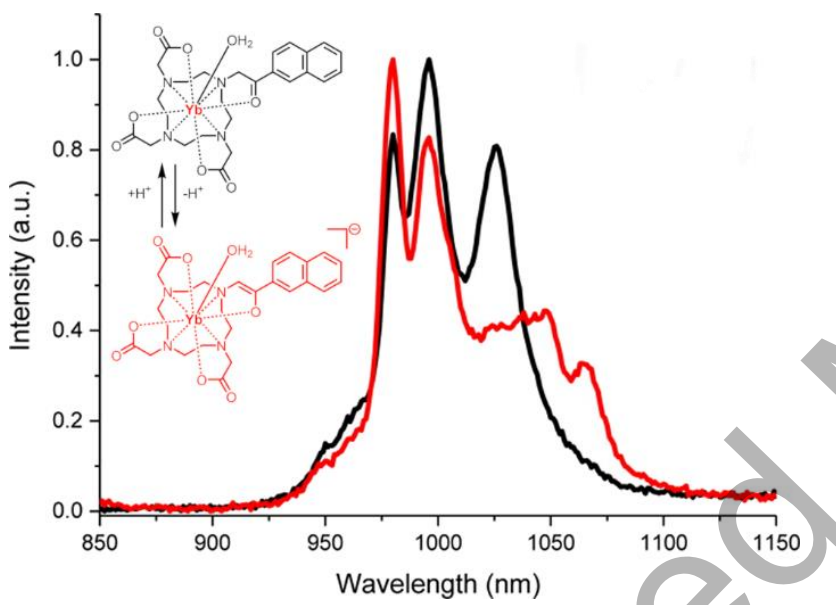

Figure 2. Emission spectrum of a pH sensitive ytterbium complex at $\mathrm{pH} 8$ (black curve) and 12.5 (red curve), in $\mathrm{D}_{2} \mathrm{O} .{ }^{[23]}$ Adapted with permission. Copyright 2015 ACS.

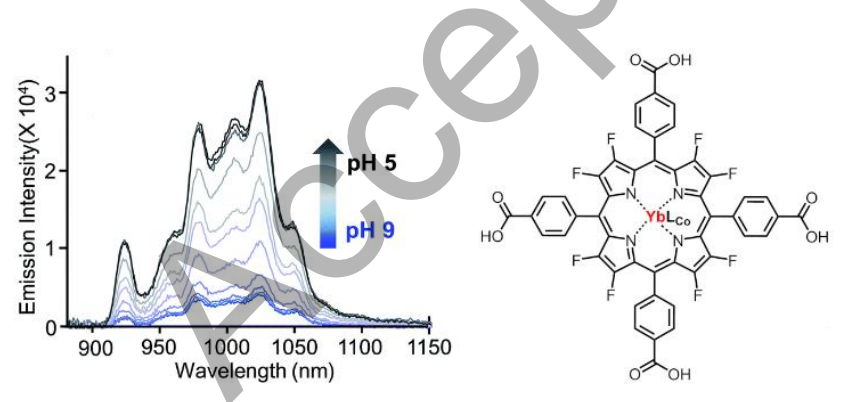

Figure 3. Luminescence spectra of a porphirinate ytterbium complex, $\mathrm{L}_{\mathrm{co}} \mathrm{stands}$ for (cyclopentadienyl)tris(di(methyl- $\mathrm{d}_{3}$ )phosphito)cobaltate) at $\mathrm{pH}$ 5.0-9.0 in aqueous buffer. The spectra were obtained with $420 \mathrm{~nm}$ Xe lamp excitation and a $850 \mathrm{~nm}$ longpass emission filter. ${ }^{[24]}$ Adapted with permission. Copyright RSC, 2019.

The analyte can also penetrate the first coordination sphere and lead to drastic intensity and/or spectrum shape changes. Nonat Charbonnière et al demonstrated such a process in the case of fluoride sensing. ${ }^{[25]}$ In water, their cyclen-based complexes can sequestrate fluoride anion through the formation of fluoride bridged dinuclear systems with high association constants (Figure
4). The replacement of a water molecule with a fluoride ion in the coordination sphere leads to a significant increase of NIR emission intensity. Interestingly, when a similar replacement occurred on a tetrapicolyl-appended cyclen complex, without the formation of bridged dinuclear complexes, the main observation was a change of CF splitting similar to the case of figure 2. ${ }^{[26]}$

Mercury(II) sensing could also be demonstrated by Jin, Tanner, Wong et al, ${ }^{[27]}$ with a scaffold combining a cationic cyclen based ytterbium complex linked to a carbodithioate-rhodamine sensing unit. Both rhodamine visible emission at $596 \mathrm{~nm}$ and ytterbium based NIR emission at $980 \mathrm{~nm}$ are observed upon UV excitation, and are enhanced upon the addition of $\mathrm{Hg}$ (II) and the opening of the rhodamine unit. A similar turn ON sensor with dual channel for detection was obtained with an ytterbium porphyrinate / rhodamine scaffold. ${ }^{[28]}$

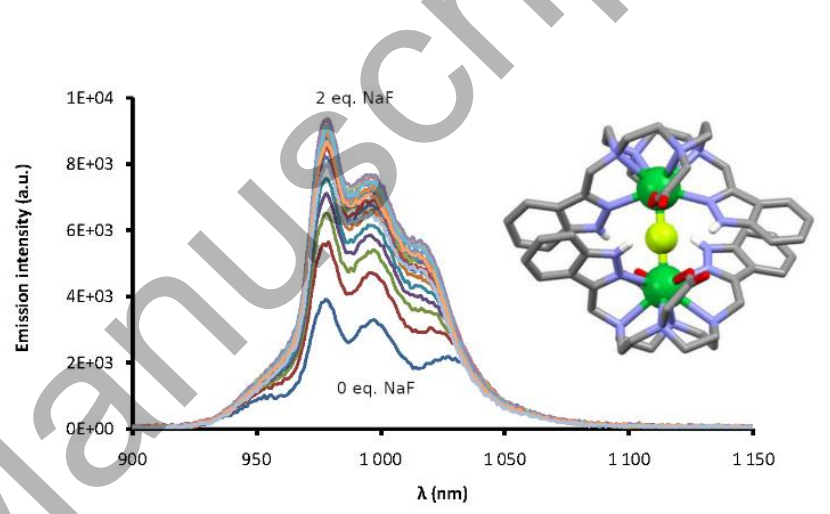

Figure 4. Steady state emission spectroscopic titration of a solution of $\left[\mathrm{YbL}\left(\mathrm{H}_{2} \mathrm{O}\right)\right] \mathrm{Cl}\left(\mathrm{L}=\mathrm{a}\right.$ cyclen based ligand with two indazolyl moieties, $\lambda_{\mathrm{ex}}=295$ $\left.\mathrm{nm}, \mathrm{pH} 7.4,0.01 \mathrm{M} \mathrm{TRIS} / \mathrm{HClO}_{4}\right)$ as a function of the number of sodium fluoride equivalents ( 0 to 6.2 , not corrected for dilution), and X-ray crystal structure of the $\left[(\mathrm{YbL})_{2} \mathrm{~F}\right]^{+}$dimer. Adapted with permission. ${ }^{[25]}$ Copyright 2018 , Wiley.

The possibility of collisional quenching between triplet state and dioxygen provides another way to affect lanthanide-based emission, either by perturbing the sensitization from an antenna triplet state or by offering a deactivation pathway through backenergy transfer to the ligand triplet state (Figure 1). In 2015, Faulkner et al. showed a first example in a pyrene appended ytterbium complex (Figure 5). ${ }^{[29]}$ In this system, energy separation between the triplet state of pyrene $\left(17500 \mathrm{~cm}^{-1}\right)$ and the ${ }^{2} \mathrm{~F}_{5 / 2}$ emissive state is very large, causing slow energy transfer rate allowing collisional quenching by oxygen to occur faster. As a result, NIR emission strongly depend on oxygen concentration and, in aerated solution, singlet oxygen formation partially prevents ytterbium emission while no back-energy transfer is involved. In contrast, Zhang et al published in 2017 a series of porphyrin like ligands with tuned triplet state showing that with adapted energy separation (3486 and $1975 \mathrm{~cm}^{-1}$ ), an energy transfer faster than the rate of oxygen quenching occurs, leading to complexes that are insensitive to oxygen. For complexes with lower energy separations $\left(1152 \mathrm{~cm}^{-1}\right)$, back energy transfer is operative and results in oxygen and temperature dependent emission. ${ }^{[30]}$ Oxygen sensing can also be realized by a different mechanism, ie. by reaction with the antenna to change its sensitization ability. In complexes bearing an anthracene antenna, oxygen is believed to react with anthracene, modifying its energy levels, with little effect on the ytterbium complex emission and an enhancement of that of the neodymium complex. ${ }^{[31]}$ Finally, 
among other examples with chemical species, we can briefly mention a water-soluble $\mathrm{Yb}$ porpholactone with a glucose moiety which NIR emission was specifically switched on in the presence of glucose oxidase (GOx), the process being reversible upon free glucose addition. ${ }^{[32]}$

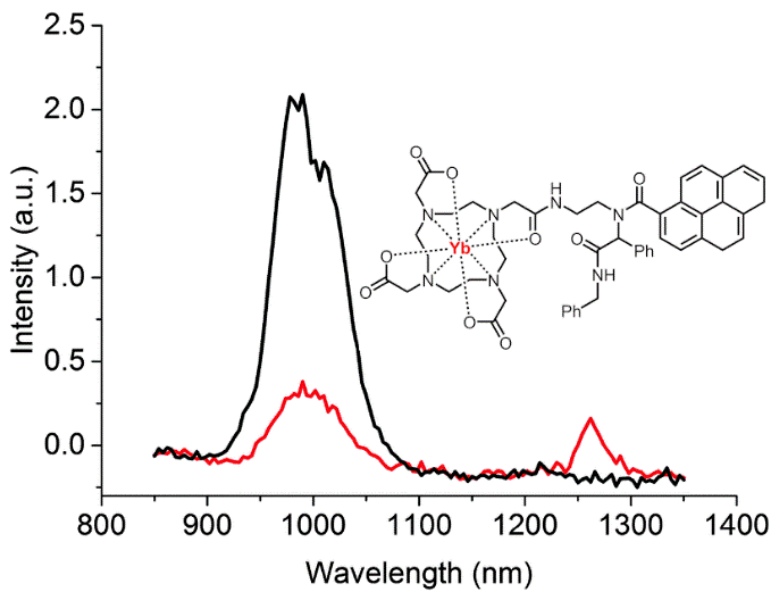

Figure 5. Emission spectra obtained following excitation at $337 \mathrm{~nm}$ for a methanolic solution of a pyrene appended ytterbium complex under aerated (red line) and degassed (black line) conditions, and showing emission from ytterbium $\left({ }^{2} \mathrm{~F}_{5 / 2}-{ }^{2} \mathrm{~F}_{7 / 2}, 980 \mathrm{~nm}\right)$ and dioxygen $\left({ }^{1} \mathrm{O}_{2}-{ }^{3} \mathrm{O}_{2}, 1270 \mathrm{~nm}\right){ }^{[29]}$ Adapted with permission, Copyright 2015, RSC.

\section{Switching induced by a change in the medium physical properties}

Compared with the previous systems, the switching mode in the following section is less specific since the integrity of the molecular species is fully retained, and only their environment is modified. Specifically, for systems operating in dilute solution, the physical properties of the solvent (polarity, viscosity, organization...) can affect the emission process either by modifying light absorption or by changing the photophysical behavior of the antenna ligand or the non-radiative processes.

First, a matrix with anisotropic optical properties, if adequately chosen, can affect the efficiency of light propagation to the complex and then light emission. This purely physical effect was demonstrated by Binnemans et al., in a Liquid Crystal (LC) cell which phase (cholesteric or nematic) can be modified by applying an electric field, therefore controlling the phosphor excitation. ${ }^{[33]}$ The emissive complexes $\left[\mathrm{Ln}(\mathrm{TTA})_{3}(\right.$ phen $\left.)\right](\mathrm{Ln}=\mathrm{Yb}, \mathrm{Nd}$, phen $=$ 1,10-phenanthroline) were doped into a chiral nematic (cholesteric) phase which strongly scatters the excitation light. Under the application of an electric field, and subsequent transition to a nematic phase (lower light scattering efficiency), a decrease of emission was observed. The contrasts, which depend in principle on the LC nature and properties, cell thickness and phosphor concentration, were of 3 to $1(\mathrm{Ln}=\mathrm{Nd})$ and 1.5 to $1(\mathrm{Ln}=\mathrm{Yb})$, significantly lower than the ones measured for similar cells doped with europium complexes. ${ }^{[34]}$

The solvent polarity and viscosity can also affect in a drastic way the antenna ligand photophysical behavior by mechanisms such as excimer formation, ${ }^{[35]}$ charge transfer state stabilization ${ }^{[36]}$ or excited-state intramolecular proton transfer (ESIPT). ${ }^{[37]}$ Therefore solvent dependent emission was characterized for several NIR emitting lanthanide complexes. Although this strategy was not used to achieve a switching system on purpose, it illustrates how the intrinsic switching behavior of the antenna can be transferred to a lanthanide complex to potentially obtain luminescent sensors. In the following, we choose two particularly informative examples.

Pyrene tendency to change from a purely monomeric fluorescence to a less structured and red-shifted excited dimer (or excimer) emission was used to tune NIR lanthanide emission by Ung et al. ${ }^{[35]}$ The less structured emission, assigned to the excimer formation is obtained upon concentration or solvent polarity increases. In THF or $\mathrm{CH}_{2} \mathrm{Cl}_{2}$, solutions of the $\mathrm{di}(1$ pyrenyl)phosphoryl acetophenonate complexes of ytterbium(III) and neodymium(III) (Figure 6) feature the well-structured pyrenecentered emission, with no emission from the lanthanide core because of poor sensitization. However, the excimeric emission at $21000 \mathrm{~cm}^{-1}(475 \mathrm{~nm})$ was evidenced in polar solvent, such as DMSO or acetone, accompanied by characteristic emission line of $\mathrm{Nd}(\mathrm{III})$ and $\mathrm{Yb}(\mathrm{III})$. The postulated sensitization process combines singlet excimer formation, ISC to the triplet excimer state and transfer to the $L n^{*}$ state, the latter being more efficient for ytterbium (emission quantum yield of $12.8 \%$ ) than for neodymium $(1.9 \%)$. This is likely because the neodymium emissive state is closer in energy to the excimeric triplet state, which allows significant back-transfer of energy to the ligand.

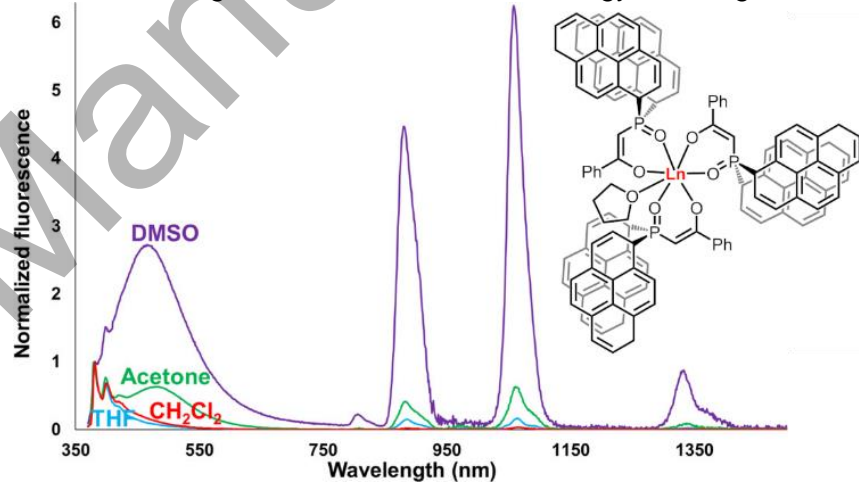

Figure 6. Emission spectra of tris(di(1-pyrenyl)phosphoryl acetophenonate) neodymium complex in various solvents $\left(2.6 \times 10^{-6} \mathrm{~mol} \mathrm{~L}^{-1}\right)$. Excitation at 355 $\mathrm{nm}$. Similar results are obtained for $\mathrm{Ln}=\mathrm{Yb} \cdot{ }^{[35]}$ Adapted with permission, Copyright 2018, ACS.

In 2020, De Bettencourt-Dias et al. published a lanthanide based luminescent viscosity sensor ${ }^{[36]}$ with either one- or two-photon excitation, that takes advantage of the modification of charge transfer states population (involving twisted intramolecular charge transfer states) upon viscosity change. Their homoleptic $\mathrm{Yb}(\mathrm{III})$ complex features a carbazole / dipicolinato $\mathrm{CPAD}^{2-}$ ligand with a donor/acceptor structure (Figure 7). This causes an NIR emission intensity increase upon viscosity increase in methanol/glycerol mixtures. The authors ruled out possible influence of oxygen concentration or solvent polarity thus demonstrating that viscosity alone has an impact on emission. 


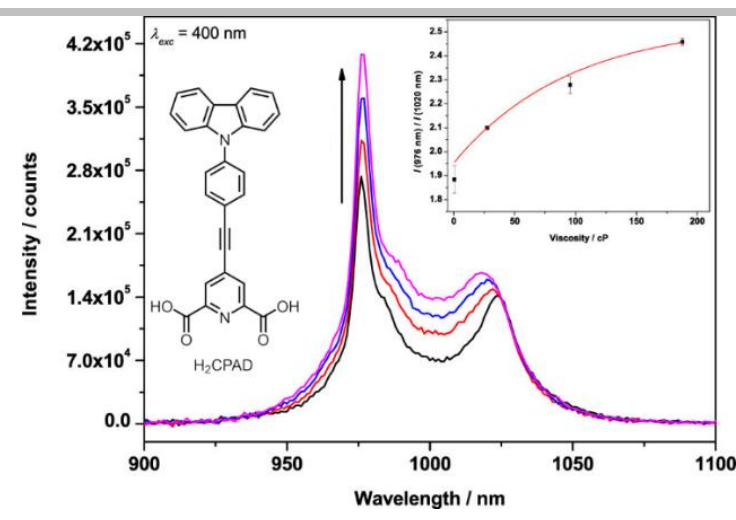

Figure 7. Structure of $\mathrm{H}_{2} \mathrm{CPAD}$ and emission spectra of $\mathrm{K}_{3}\left[\mathrm{Yb}(\mathrm{CPAD})_{3}\right]\left(\lambda_{\mathrm{exc}}=\right.$ $400 \mathrm{~nm}$ ) with increasing viscosities. The inset shows the plot of the emission intensity ratios at 976 and $1020 \mathrm{~nm}$ as a function of viscosity. Mixtures of $\mathrm{MeOH} /$ glycerol at various ratios were used as solvents with variable viscosity. ${ }^{[36]}$ Adapted with permission. Copyright 2020, ACS.

\section{Thermo-luminescence switching}

Temperature recently emerged as a new stimulus to toggle the luminescence of lanthanide. The so-called optical thermometers are thought to play a major role in bio-sensing application, ${ }^{[38]}$ in nanoscale ${ }^{[39]}$ devices and in detecting hot spot in plastic bonded explosives. ${ }^{[40]}$ Although thermal switching of lanthanides emitting in the visible range $(\mathrm{Eu}(\mathrm{III}), \mathrm{Tb}(\mathrm{III}), \mathrm{Dy}(\mathrm{III}))$ were extensively studied and reviewed, ${ }^{[41]}$ NIR luminescence modulation resulting from a temperature change has been less investigated in molecular materials. As the temperature increases, the lanthanide luminescence may either decrease or increase in a sizable way, or experience a band modulation. In the following, we will highlight recent examples of these categories based on $\mathrm{Yb}(\mathrm{III})$ and $\mathrm{Nd}$ (III) NIR emitters.

First, concerning the emission decrease with increasing the temperature, Murugesu et al. ${ }^{[22]}$ recently achieved a solid-state $\mathrm{Yb}$ (III) ion based optical thermometer. A dinuclear specie $\left[\mathrm{Yb}_{2}(\text { valdien })_{2}\left(\mathrm{NO}_{3}\right)_{2}\right]$ (valdien = the doubly deprotonated form of N1,N3-bis(3-methoxysalicylidene) diethylenetraimine) showed an effective luminescence decrease upon increasing the temperature from $80 \mathrm{~K}$ to $320 \mathrm{~K}$ (Figure 8), which origin remains unclear. The characteristic lines of $\mathrm{Yb}(\mathrm{III})$ emission $\left({ }^{2} \mathrm{~F}_{5 / 2} \rightarrow{ }^{2} \mathrm{~F}_{7 / 2}\right)$ also experienced a sizeable broadening with increasing temperature.

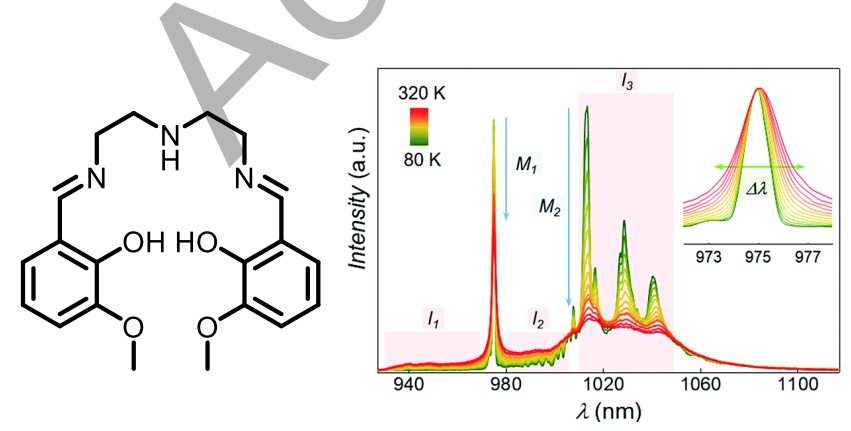

Figure 8. $\mathrm{H}_{2}$ valdiene ligand structure (left). Thermal quenching of $\left.\left[\mathrm{Yb}_{2} \text { (valdien }\right)_{2}\left(\mathrm{NO}_{3}\right)_{2}\right]$ when the temperature is raised from $80 \mathrm{~K}$ to $320 \mathrm{~K}$ (right). The inset shows the sizeable broadening of the (normalized) luminescence band at $975 \mathrm{~nm}$ as a function of the temperature. ${ }^{[42]}$ Reproduced with permission. Copyright 2019, RSC.
Zhang et al. also reported the thermal quenching of luminescence of an $\mathrm{Yb}$ (III) monometallic complex, where the metal ion is sandwiched between a cis-porphodilactone and the Kläui's ligand. ${ }^{[43]}$ The luminescence experienced an 11-fold decrease by increasing the temperature from $77 \mathrm{~K}$ down to $293 \mathrm{~K}$. The authors have ruled out the possibility of thermal repopulation of vibrational levels since the relative intensities of the different emission lines were unchanged. Interestingly, they have performed luminescence switching under air-saturated and $\mathrm{N}_{2}$ saturated solutions and have clearly demonstrated that under inert atmosphere, the effect of temperature was cancelled. As a result, the still elusive quenching mechanism should be related to temperature-dependent oxygen diffusion in the solution combined with thermal repopulation of the triplet state.
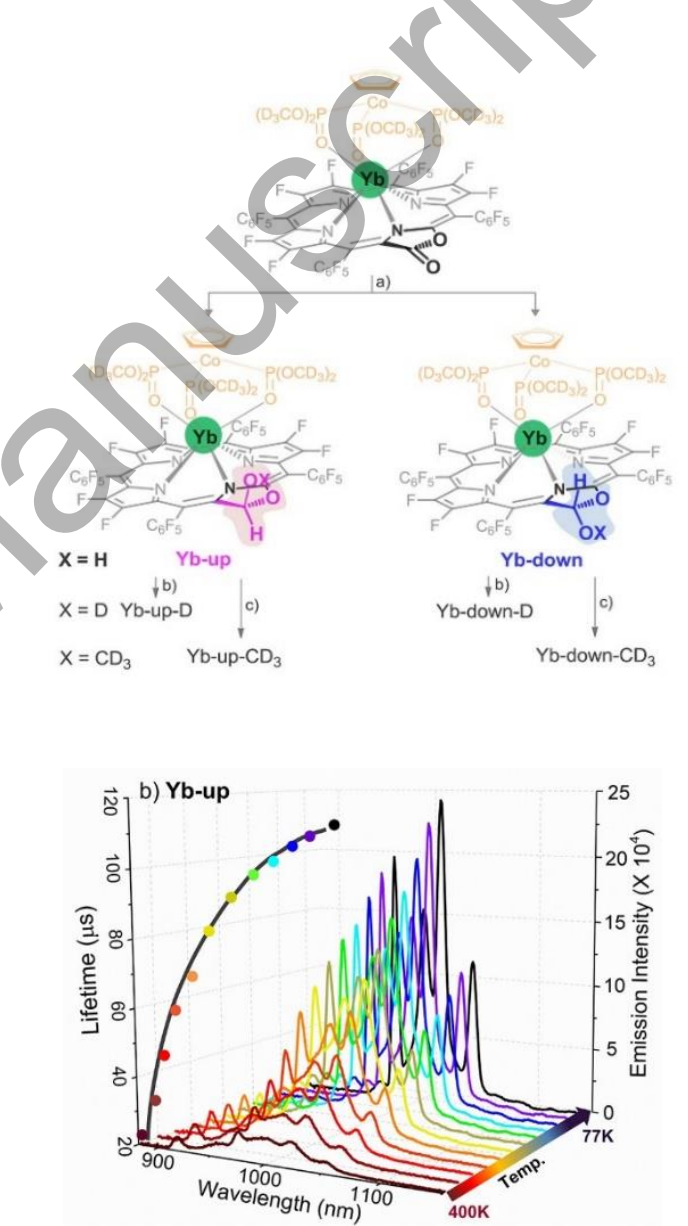

Figure 9. (Top) Compounds $\mathrm{Yb}$-up and $\mathrm{Yb}$-down featuring the $\mathrm{O}-\mathrm{H}$ vibrator in the up or down orientation. (Bottom) change in the luminescence of $\mathrm{Yb}$-up as a function of the temperature, from $77 \mathrm{~K}$ to $400 \mathrm{~K}$ in PMMA films. The dotted line corresponds to the variation of the luminescence lifetime with temperature. ${ }^{[43]}$ Adapted with permission. Copyright 2018, American Chemical Society.

The same group further reported a novel monometallic system based on the previous complex (Figure 9). ${ }^{[43]}$ In this case, the cisporphodilactone ligand was replaced by a porpholactol ligand featuring a hemiacetal function with two possible orientations for the $\mathrm{O}-\mathrm{H}$ vibrator group (up or down with respect to the lanthanide core). Both complexes displayed reversible thermosensitive and oxygen-independent behavior in PMMA films with various relative thermosensitivities $\left(6.0 \% \mathrm{~K}^{-1}\right.$ and $\left.3.8 \% \mathrm{~K}^{-1}\right)$ in the range $77 \mathrm{~K}-$ 
$400 \mathrm{~K}$. When the hydroxylic groups were methylated $\left(\mathrm{O}-\mathrm{CD}_{3}\right.$ instead of $\mathrm{O}-\mathrm{H}$ ), their NIR luminescence thermal quenching vanished. This result strongly suggests that the luminescence quenching is due to the lanthanide excited state deactivation through $\mathrm{O}-\mathrm{H}$ vibration. The different thermosensitivities between "up" and "down" complexes were ascribed to the intramolecular hydrogen bonding featured in the "up" orientation of the $\mathrm{O}-\mathrm{H}$ vibrator group. Since the $\mathrm{O}-\mathrm{H}$ bond vibration is also sensitive to solvent viscosity, a clear dependence of the emission intensity with viscosity was also evidenced.

The same year, Pan et al. have reported on ESIPT-modulation of the $\mathrm{Yb}$ (III) ion NIR luminescence. ${ }^{[37]}$ The complex features thermosensitivity at the solid-state from 100 to $300 \mathrm{~K}$ (Figure 10). Since the surrounding solvent may influence the proton transfer, aprotic solvents such as DMF, cyclohexane or acetone provided longer lifetime concomitant with higher luminescence intensities. However, the correlation between the luminescence quenching and the intramolecular hydrogen bonding could not be clearly evidenced

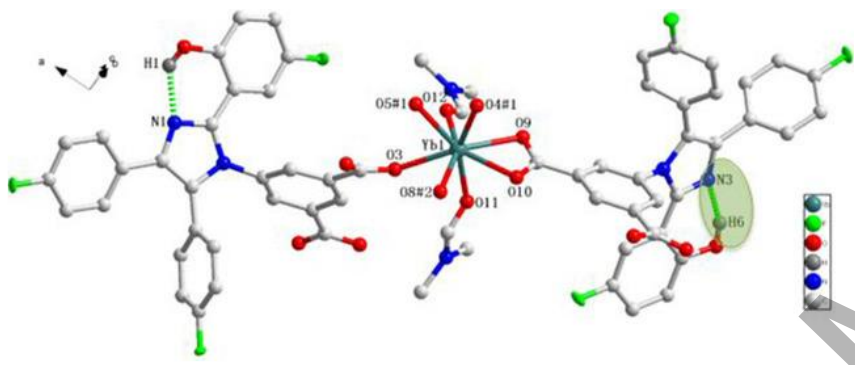

Figure 10. Crystal structures of LIFM-43(Yb) featuring an octacoordinated $\mathrm{Yb}^{3+}$ center. Yb, light blue; F, green; O, red; $\mathrm{C}$, light gray; $\mathrm{N}$, blue; $\mathrm{H}$, dark gray. The green dotted lines and the colored ovals denote the ESIPT sites of the ligand. ${ }^{[37]}$ Adapted with permission. Copyrigh 2018, Wiley.

In another recent work, Zhou et al. ${ }^{[44]}$ described the thermal quenching of a neodymium(III) coordination compound with a pyridine dicarboxylate ligand Nd-PDC. These authors have suggested that the $\mathrm{Nd}(\mathrm{III})$ luminescence $\left({ }^{4} \mathrm{~F}_{3 / 2} \rightarrow{ }^{4} \mathrm{I}_{11 / 2}\right)$ modulation was due to lattice vibrations and electron-phonon interactions as the temperature was increased from $298 \mathrm{~K}$ to $368 \mathrm{~K}$ (Figure 11). The highest relative sensitivity was obtained at $318 \mathrm{~K}$ and amounted for $0.181 \% \mathrm{~K}^{-1}$. To the best of our knowledge, this example is the only one reported to date, regarding temperaturedependent luminescence of a monometallic $\mathrm{Nd}^{3+}$-based complex.

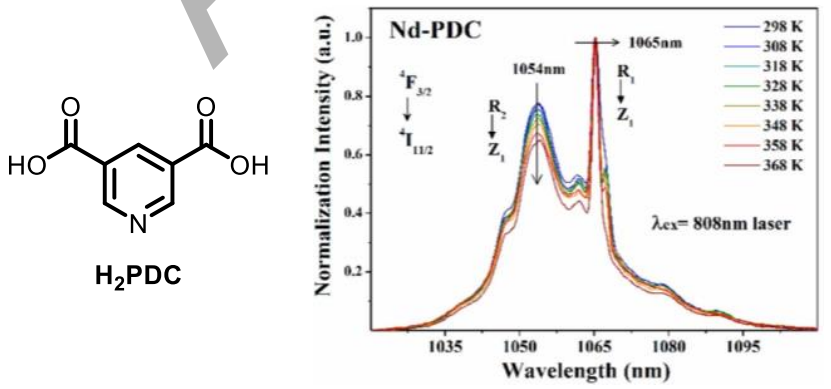

Figure 10. Structure of $\mathrm{H}_{2} \mathrm{PDC}$ ligand (left). Continuous decrease in luminescence of Nd-PDC solid sample with increasing the temperature (right). A laser excitation in the $f-f$ lanthanide bands was performed at $808 \mathrm{~nm}$ to monitor this thermal process. ${ }^{[44]}$ Reproduced with permission. Copyright 2020, Elsevier.
As far as emission increase with increasing the temperature is concerned, a first example was reported for a monometallic $\left[\mathrm{Yb}(\mathrm{tta})_{3} \mathrm{DFQZ}\right]$ complex by Fu et al. ${ }^{[45]}$ In PMMA films (Figure 11), under nitrogen atmosphere, both the lifetimes and the quantum yield improved when the temperature increased, as opposed to films exposed to oxygen. In the solution state, though, quantum yield measurement performed at $198 \mathrm{~K}$ and $318 \mathrm{~K}$ in $\mathrm{N}_{2}$-saturated solution clearly paralleled the intensity increase with the temperature. However, luminescence lifetime followed an opposite trend. At low temperature, the lifetime was $18.0 \mu$ s while at $318 \mathrm{~K}$ the lifetime decreased to $15.7 \mu \mathrm{s}$. From these results, the authors inferred that the sensitization efficiency of the $\mathrm{Yb}(\mathrm{III})$ ion was increased with temperature probably because of a crystal field change surrounding the metal. Based on these outcomes, the authors proposed an attractive example of self-calibrated optical thermometer with a temperature resolution of $0.5 \mathrm{~K}$.

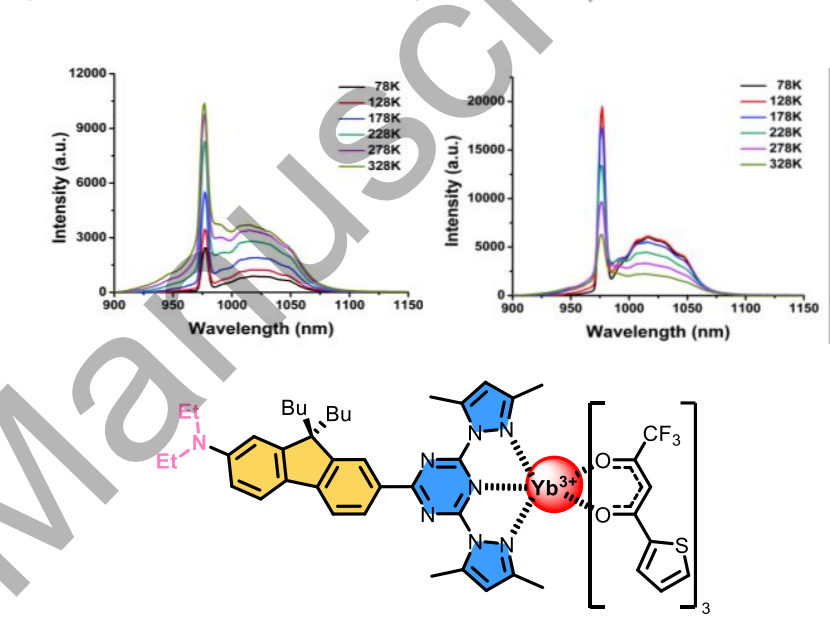

Figure 11. (Lower panel) Structure of $\left[\mathrm{Yb}(\mathrm{tta})_{3} \mathrm{DFQZ}\right]$ featuring the $\mathrm{D}-\pi-\mathrm{A}$ structure $(D=$ electron donating moiety in pink; $A=$ electron withdrawing moiety in blue; $\pi=9,9$-dibutylfluorene group in yellow). (Upper panel) Variabletemperature luminescence spectra of PMMA-[Yb(tta) $\left.{ }_{3} \mathrm{DFQZ}\right] 10 \% \mathrm{wt}$, under $\mathrm{N}_{2}$ (left) and $\mathrm{O}_{2}$ (right) atmosphere. Under $\mathrm{N}_{2}$ gaz, the luminescence intensity increased while the opposite trend was observed under $\mathrm{O}_{2}$. Excitation was set

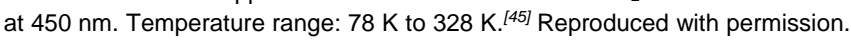
Copyright 2015, RSC.

In another example, $\mathrm{Li}$ et al. ${ }^{[46]}$ have reported the thermosensitivity of mixed-lanthanide MOF $\mathrm{Nd}_{0.5} \mathrm{Yb}_{0.5}$ TPTC (where TPTC stands for 1,1':4',1"-terphenyl-3,3",5,5"tetracarboxylic acid). At room temperature and when excited at $808 \mathrm{~nm}$, the emission spectrum features the characteristic emissions of $\mathrm{Nd}(\mathrm{III})$ at $903 \mathrm{~nm}, 1062 \mathrm{~nm}$ and $1336 \mathrm{~nm}$ corresponding to $\left.{ }^{4} \mathrm{~F}_{3 / 2} \rightarrow{ }^{4}\right|_{9 / 2},\left.\quad{ }^{4} \mathrm{~F}_{3 / 2} \rightarrow{ }^{4}\right|_{11 / 2}, \quad$ and $\left.{ }^{4} \mathrm{~F}_{3 / 2} \rightarrow{ }^{4}\right|_{13 / 2}$ transitions, respectively, as well as one at $1026 \mathrm{~nm}$ assigned to the $\mathrm{Yb}$ (III) ion $\left({ }^{2} \mathrm{~F}_{5 / 2} \rightarrow{ }^{2} \mathrm{~F}_{7 / 2}\right)$. Upon lowering the temperature from $328 \mathrm{~K}$ down to $293 \mathrm{~K}$, the emission band at $1026 \mathrm{~nm}$ increased by 4.6 -fold while the $1062 \mathrm{~nm}$ band experienced a rather slight rising. This was rationalized with an efficient thermally activated energy transfer from $\mathrm{Nd}$ (III) to $\mathrm{Yb}$ (III) ions, due to the existence of dimetallic unit featuring $\mathrm{Nd}(\mathrm{III})$ and $\mathrm{Yb}$ (III) ions in very close contact in the mixed MOF material. Additionally, Zhou et al. ${ }^{[44]}$ have engineered mixed lanthanide complexes $\mathrm{Nd}_{1.43} \mathrm{Yb}_{0.57}$-PDC and $\mathrm{Gd}_{1.45} \mathrm{Nd}_{0.40} \mathrm{Yb}_{0.15}$-PDC. Their photoluminescence spectra after excitation at $808 \mathrm{~nm}$ feature simultaneously the very characteristic lines of $\mathrm{Nd}(\mathrm{III})$ and $\mathrm{Yb}$ (III) ions, thanks to an efficient energy transfer from $\mathrm{Nd}(\mathrm{III})$ to $\mathrm{Yb}$ (III). Upon increasing the 
temperature, both complexes displayed thermosensitive response. In particular, $\mathrm{Gd}_{1.45} \mathrm{Nd}_{0.40} \mathrm{Yb}_{0.15}$-PDC showed an intriguing luminescence change (Figure 12). From low to high temperatures, the $\mathrm{Yb}(\mathrm{III})$ ion luminescence $(1005 \mathrm{~nm})$ was quenched whereas the $\mathrm{Nd}(\mathrm{III})$ one $(1052 \mathrm{~nm})$ increased. This is again a typical case of energy back transfer controlled by the temperature. Using the ratio $I_{\mathrm{Nd}(1052)} / I_{\mathrm{Yb}(1005)}$ as thermometrics, they have determined a relative sensitivity of 0.482 to $0.439 \% \mathrm{~K}^{-1}$ with a temperature resolution of lower than $0.08 \mathrm{~K}$.

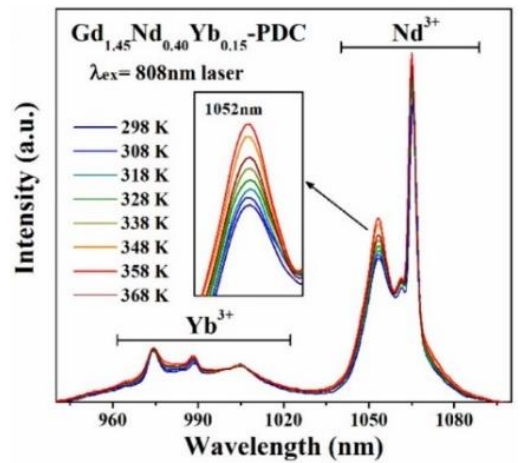

Figure 12. Luminescence modulation of $\mathrm{Gd}_{1.45} \mathrm{Nd}_{0.40} \mathrm{Yb}_{0.15}$-PDC upon rising the temperature from $298 \mathrm{~K}$ to $368 \mathrm{~K} \cdot{ }^{[44]}$ Reproduced with permission. Copyright 2020, Elsevier.

The first example of NIR lanthanide luminescence band modulation as a function of temperature was reported by Motoko et al. on $\mathrm{Yb}(\mathrm{III})$ porphyrin complexes in solution. ${ }^{[47]}$ They established the existence of hot bands due to thermal population of sublevels in the upper and ground state multiplets of the $\mathrm{Yb}(\mathrm{III})$ ion, which are the consequences of the CF splitting.

Another very recent example of modulation relying on hot bands was published by Ohkoshi et al..[48] They developed a $3 \mathrm{~d}-4 \mathrm{f}$ assembly featuring a reversible and large luminescence modulation between $10 \mathrm{~K}$ and $300 \mathrm{~K}$ (Figure 13) and obtained relative sensitivity of $4.6 \% \mathrm{~K}^{-1}$ at $50 \mathrm{~K}$, as well as temperature resolution of $0.1-1 \mathrm{~K}$.

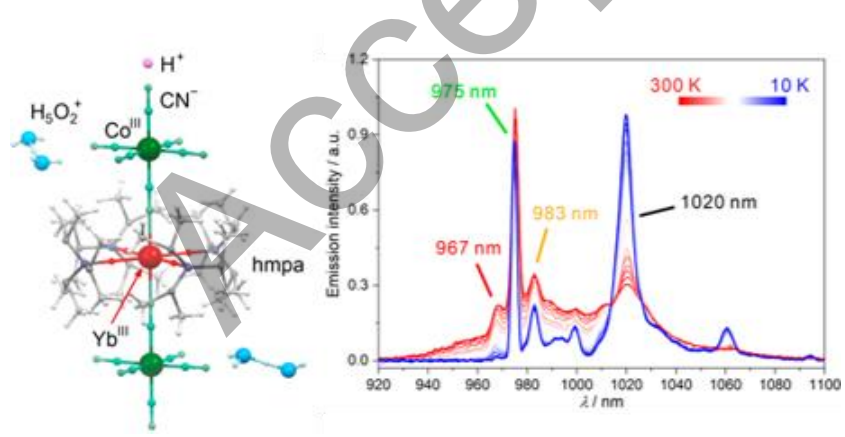

Figure 13. Structure of $\left(\mathrm{H}_{5} \mathrm{O}_{2}{ }^{+}\right)_{2}\left(\mathrm{H}^{+}\right)\left[\mathrm{Yb}^{\prime \prime \prime}(\mathrm{hmpa})_{4}\right]\left[\mathrm{Co}^{\prime \prime \prime \prime}(\mathrm{CN})_{6}\right]_{2} \cdot 0.2 \mathrm{H}_{2} \mathrm{O}$ (left). Luminescence modulation upon changing the temperature from $10 \mathrm{~K}$ to $300 \mathrm{~K}$. The emission band at $1020 \mathrm{~nm}$ strongly decreases its intensity upon warming while all emission bands in the 920-1010 nm range were found to follow the opposite trend. The excitation was set at $320 \mathrm{~nm} .{ }^{[48]}$ Adapted with permission. Copyright 2020, American Chemical Society.

\section{Redox switching}

Several articles report redox switching of lanthanide ions emission in the visible region with $\mathrm{Eu}(\mathrm{III}), \mathrm{Tb}(\mathrm{III})$ and $\mathrm{Sm}$ (III) ions incorporated in molecular complexes, ${ }^{[49]}$ in coordination polymers, ${ }^{[50]}$ in inorganic nanorods, ${ }^{[51]}$ and sometimes in complexes deposited on electrodes. ${ }^{[52]}$ They usually include a redox active unit such as a transition metal complex or an organic ligand that creates a non-radiative deactivation pathway in its oxidized state, whereas other mechanisms such as geometrical modifications under potentiostatic polarization were reported. ${ }^{[53]}$

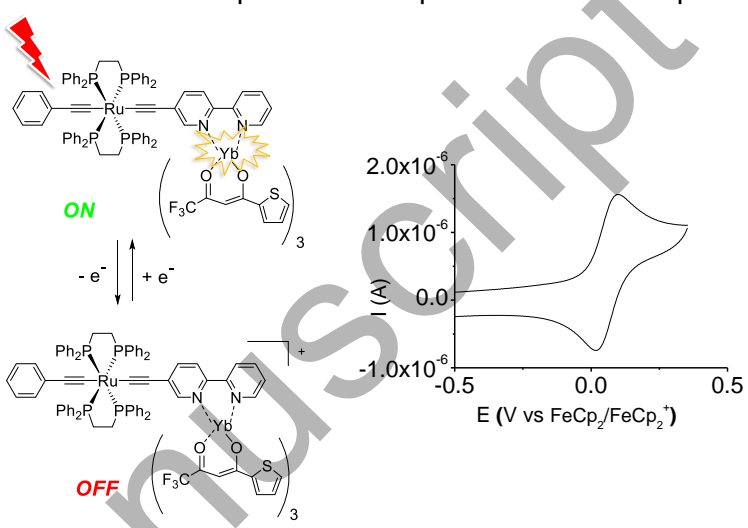

Figure 14. Redox process and $\mathrm{CV}$ trace of the $\mathrm{Ru}-\mathrm{Yb}$ complex $\left(\mathrm{CH}_{2} \mathrm{Cl}_{2}, 0.2 \mathrm{M}\right.$ $\left.\mathrm{Bu}_{4} \mathrm{NPF}_{6}, \mathrm{v}=100 \mathrm{mV} \cdot \mathrm{s}^{-1}\right) \cdot{ }^{[54]}$ Adapted with permission. Copyright 2014, ACS

As far as the NIR region is concerned, with the associations between $\mathrm{Yb}(\mathrm{III}), \mathrm{Nd}(\mathrm{III})$ ions and a redox active ruthenium acetylide complexes bearing a bipyridine chelating unit of the type

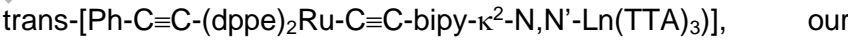
group built original $d$-f heterometallic complexes (Figure 14). ${ }^{[54]}$ Efficient sensitization in the visible range of both NIR emitters was achieved with the ruthenium-acetylide antenna, through a multiconfigurational metal-to-ligand charge transfer (MLCT) at $\lambda_{\max }=$ $460 \mathrm{~nm}$ whereas sensitization of the Eu(III) ion was not efficient owing to a too low energy level of the antenna excited state. For example, upon excitation, the characteristic line shape emission of ytterbium $\left({ }^{2} \mathrm{~F}_{5 / 2} \rightarrow{ }^{2} \mathrm{~F}_{7 / 2}\right)$ was observed (Figure 15). The luminescence of these complexes was further modulated with a redox agent ${ }^{[54]}$ and electrochemically. ${ }^{[55]}$ In the latter case, Figure 15 shows the luminescence response obtained upon oxidation at $0.8 \mathrm{~V} \mathrm{vs}$. $\mathrm{Fc}^{+} / \mathrm{Fc}$ where the emission intensity decreases of ca. $100 \%$ of its original value and further reduction lead to the recovering of $87 \%$ of the original intensity. The process can be rationalized either by the oxidation of the ruthenium acetylide moieties preventing any sensitization by an electron transfer mechanism, or by the apparition of the new excited states at c.a $1060 \mathrm{~nm}$ due to multiple transitions from HOMO- $n$ to the SOMO

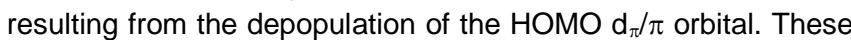
low-lying excited states can either prohibit the $\mathrm{Yb}$ (III) sensitization and/or afford a preferential non-radiative back-energy transfer pathway from the ${ }^{2} \mathrm{~F}_{5 / 2} \mathrm{Yb}$ (III) excited state. 

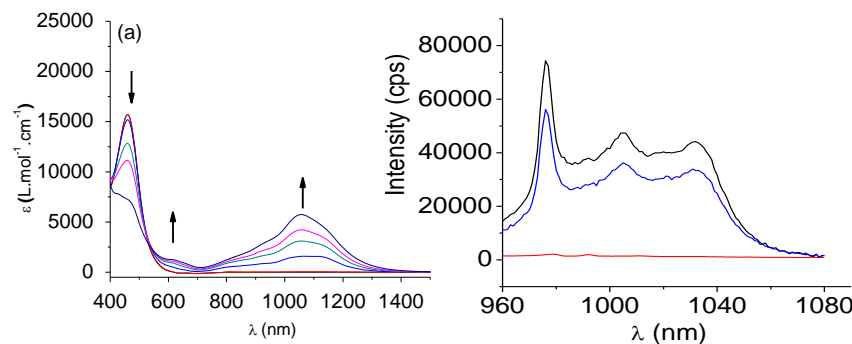

Figure 15. (left) Monitoring of the absorption spectra during the first oxidation of the $\mathrm{Yb}$ complex in an OTTLE cell $\left(\mathrm{CH}_{2} \mathrm{Cl}_{2}, 0.2 \mathrm{M} \mathrm{Bu}_{4} \mathrm{NPF}_{6}\right)$. (right) Monitoring of the emission spectra $\left(\lambda_{\mathrm{ex}}=440 \mathrm{~nm}\right)$ upon its first oxidation in an OTTLE cell $\left(\mathrm{CH}_{2} \mathrm{Cl}_{2}, 0.2 \mathrm{M} \mathrm{Bu}_{4} \mathrm{NPF}_{6}\right)$ : Initial emission spectrum in $\mathrm{CH}_{2} \mathrm{Cl}_{2}$ (black), after oxidation at $0.8 \mathrm{~V}$ vs. $\mathrm{Fc}^{+} / \mathrm{Fc}$ (red), and after reduction at $\mathrm{OV}$ (blue). ${ }^{[55}$ Reproduced with permission. Copyright 2014, ACS

Also in 2011, the Faulkner group achieved an electrochemical modulation of the NIR emission of the ytterbium ion. ${ }^{[49 c]}$ In their complex, the macrocyclic ligand derived from DO3A and bearing a redox active ferrocene moiety played the role of a redox-active antenna to sensitize and modulate the $\mathrm{Yb}$ (III) ion luminescence (Figure 16). In the neutral form of the system, upon excitation with $\lambda_{\mathrm{ex}}=425 \mathrm{~nm}$ in aqueous solution, energy transfer occurs from the ferrocene excited states to ytterbium excited state leading to $\mathrm{Yb}(\mathrm{III})$ emission. Upon oxidation, a small but significant decrease of NIR luminescence is observed. The authors hypothesized that the quenching was due to the generation of new low-lying excited states attributed to the generation of ferrocenium.
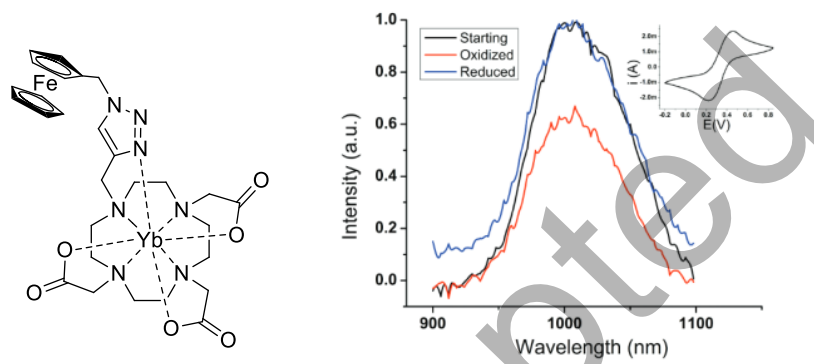

Figure 16. Chemical structure and emission spectra of the ytterbium complex after sequential oxidation and reduction $\left(\lambda_{\mathrm{ex}}=425 \mathrm{~nm}\right)$. Inset: diffusive cyclic voltammogram (2 mM in $0.1 \mathrm{M} \mathrm{NaClO}_{4}, 100 \mathrm{mV}^{-1}{ }^{-1}$, Pt gauze working electrode). ${ }^{[49 c]}$ Reproduced with permission. Copyright 2011, ACS.

The group of $\mathrm{F}$. Thomas reported in 2017 an $\mathrm{Yb}$ (III) complex involving sterically hindered phenolate moieties. ${ }^{[49 \mathrm{~d}]}$ Upon exciting the neutral form with $\lambda_{\max }=310 \mathrm{~nm}$, where the ligand absorbs, the characteristic $\mathrm{Yb}(\mathrm{III})$ emission was observed (Figure 17). The sensitization mechanism is explained with an energy transfer from the ligand excited states to the metal ion excited state. Upon oxidation, the phenoxyl radical formation $\left[\mathrm{L}-\mathrm{Yb}-\mathrm{NO}_{3}\right]^{+}$, verified with EPR spectroscopy, led to $95 \%$ quenching and the formation of the doubly oxidized specie $\left[\mathrm{L}-\mathrm{Yb}-\mathrm{NO}_{3}\right]^{2+}$ led to total quenching, however regeneration upon reduction was not reported. The quenching mechanism was explained by the population of the singlet radical excited state followed by non-radiative deactivation, or by the fact that the triplet excited state in the radical is too low to populate the $\mathrm{Yb}(\mathrm{III})$ ion excited state.
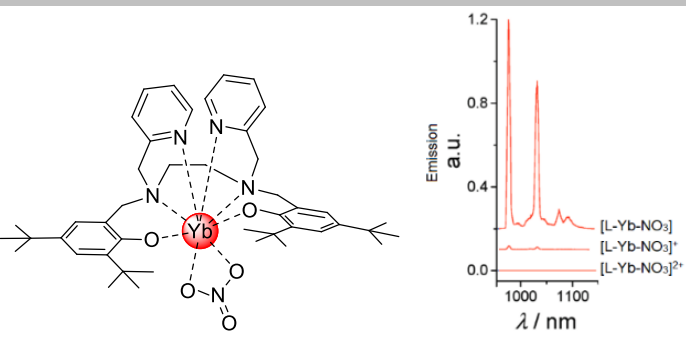

Figure 15. Chemical structure of $\left[\mathrm{L}-\mathrm{Yb}-\mathrm{NO}_{3}\right]$ and luminescence spectra $(0.5 \mathrm{mM}$ $\mathrm{CH}_{3} \mathrm{CN}+0.1 \mathrm{M}$ tetrabutylammonium perchlorate as electrolyte) at $77 \mathrm{~K}$ of the lanthanide complexes under various oxidation states. ${ }^{[49 d]}$ Reproduced with permission. Copyright 2017, RSC.

In 2018, the same group was able to achieve new sevencoordinated lanthanide complexes including three NIR emitters ( $\mathrm{Nd}(\mathrm{III}), \mathrm{Yb}(\mathrm{III})$, and $\mathrm{Er}(\mathrm{III})$ ) with a tripodal redox active ligand presented in Figure 18. ${ }^{[56]}$ The authors showed that the three complexes display three successive one-electron oxidations of the phenolate moieties to phenoxyl radicals. In their neutral form, the absorption spectrum of the complexes exhibits an absorption band at around $\lambda_{\max }=400 \mathrm{~nm}$ and the emission spectra of the complexes $\left(\lambda_{\mathrm{ex}}=405 \mathrm{~nm}\right)$ were characteristic of each $\mathrm{Ln}(\mathrm{III})$ ion due to the antenna effect of the phenolate ligands. Upon addition of a one-electron oxidant, the luminescence of the three complexes was quenched by 83,92 , and $79 \%$ for $\mathrm{L}-\mathrm{Yb}^{+}, \mathrm{L}-\mathrm{Nd}^{+}$, and $\mathrm{L}^{-\mathrm{Er}^{+}}$, respectively. This was ascribed to a non-radiative intramolecular deactivation of the oxidized ligand-excited state preventing energy transfer to the lanthanide ion emissive state. Similar observations were reported for a closely related tris(phenolato) $\mathrm{Yb}$ (III) complex. ${ }^{[49 \mathrm{e}]}$

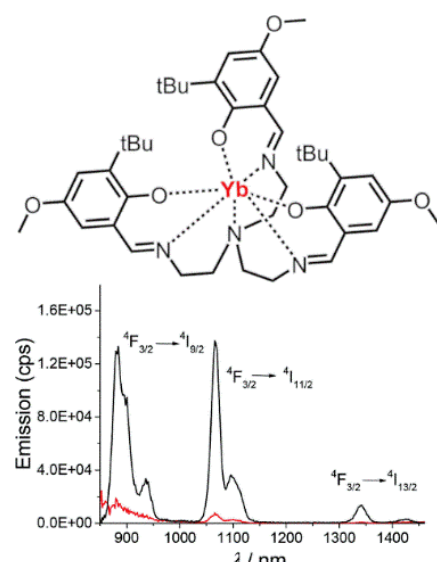

Figure 18. Chemical structure of the complexes $(\mathrm{Ln}=\mathrm{Yb}, \mathrm{Er}, \mathrm{Nd})$ and emission spectra of $0.5 \mathrm{mM} \mathrm{CH}_{3} \mathrm{CN}$ solutions at $77 \mathrm{~K}$ of the $\mathrm{Nd}$ (III) one. The black lines represent the neutral complexes, the red lines represent the chemically generated monocation (addition of one molar equivalent of one-electron oxidan to the solutions of the neutral precursors). ${ }^{[56]}$ Reproduced with permission Copyright 2018, RSC. 

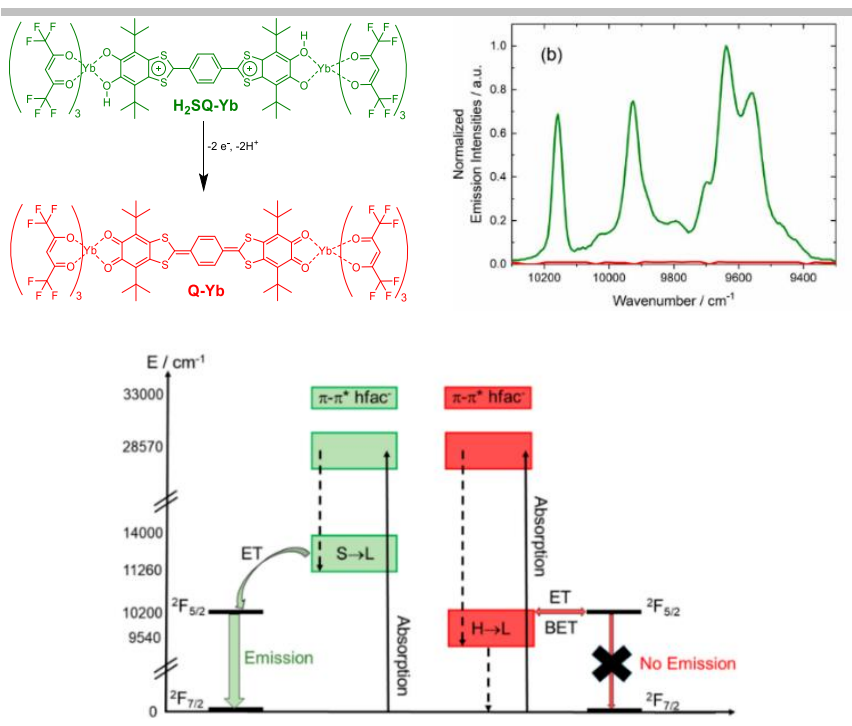

Figure 19 (top left) Chemical structure, (top right) emission spectrum evolution upon oxidation at room temperature in $\mathrm{CH}_{2} \mathrm{Cl}_{2}\left(\mathrm{C}=4 \times 10^{-5} \mathrm{M}, \lambda_{\mathrm{ex}}=600 \mathrm{~nm}\right)$. (bottom) Proposed sensitization and quenching mechanism in the neutral and oxidized form, respectively (ET: energy transfer, S: SOMO, L: LUMO, H: HOMO, BET: back energy transfer). ${ }^{[57]}$ Reproduced with permission. Copyright 2018 , MDPI.

Beside the above examples, F. Pointillart et al. recently published a new original $\mathrm{Yb}(\mathrm{III})$ based NIR switch that can be operated by chemical oxidation. ${ }^{[57]}$ Their strategy was based on an extended tetrathiafulvalene (TTF) ligand, widely known to undergo reversible redox processes, and two semiquinone moieties to coordinate two $\mathrm{Yb}$ (III) ions (Figure 19). ${ }^{[58]}$ In terms of luminescence, it is recognized that the low energy ILCT of the neutral form of the extended TTF is a good sensitizer of $\mathrm{Yb}(\mathrm{III})$ ion luminescence. Therefore, excitation at $16670 \mathrm{~cm}^{-1}$ (or lower) led to an efficient energy transfer from the excited state of the neutral form of the ligand $\left(12500 \mathrm{~cm}^{-1}\right)$ into the $\mathrm{Yb}$ (III) ion excited state (10 $\left.200 \mathrm{~cm}^{-1}\right)$. In contrast, in the oxidized form obtained by addition of an excess of $\mathrm{MnO}_{2}$ in solution, the significant changes in the electronic structure led to the total emission quenching owing to an efficient back energy transfer from ytterbium excited state $\left(10200 \mathrm{~cm}^{-1}\right)$ to the almost overlapping excited state generated upon ligand oxidation $\left(9800 \mathrm{~cm}^{-1}\right)$.

\section{Optical switching (photochromism)}

The switching of Ln emission with organic photochromic units has been considered by scientist for several years. It has been achieved mainly with the red emissive Eu(III) ion in coordination complexes, thanks to ligand field modifications with a photochromic reaction ${ }^{[59]}$ or to the control of a resonant energy transfer between a photochromic unit and the emissive ion ${ }^{[16 a, 60]}$ by alternating UV and visible lights. This process was also achieved with photochromic MOFs ${ }^{[61]}$ or POMs. ${ }^{[62]}$

The fatigue resistance of most dithienylethene (DTE) molecules makes them quite unique among photochromic systems. ${ }^{[1 e]}$ They are switched from a non-conjugated form to a conjugated form upon UV light irradiation, and converted back using a visible irradiation. In our first work toward NIR emission modulation, we described the study of two lanthanide complexes ( $\mathrm{Ln}=\mathrm{Eu}$ and $\mathrm{Yb}$ ) built with a DTE unit combined with a dipicolinic amide ligand. ${ }^{[59 \mathrm{~d}]}$ We found that with the $\mathrm{Eu}(\mathrm{III})$ ion, the closing of the DTE leads to a partial quenching of emission, owing to an expected energy transfer. In contrast, with the $\mathrm{Yb}$ (III) ion, the ring closure can be used for luminescence turn on in the NIR range by using the closed DTE as a sensitizer (Figure 20). Excitation of the cyclized DTE unit in the large absorption band of the complex at $580 \mathrm{~nm}$ concomitantly promotes the ring opening reaction and the decrease of the NIR luminescence. Although the observed emission was weak, this work demonstrated a new strategy to control $\mathrm{Yb}$ (III) luminescence using the DTE photochromic unit as a versatile chromophore.

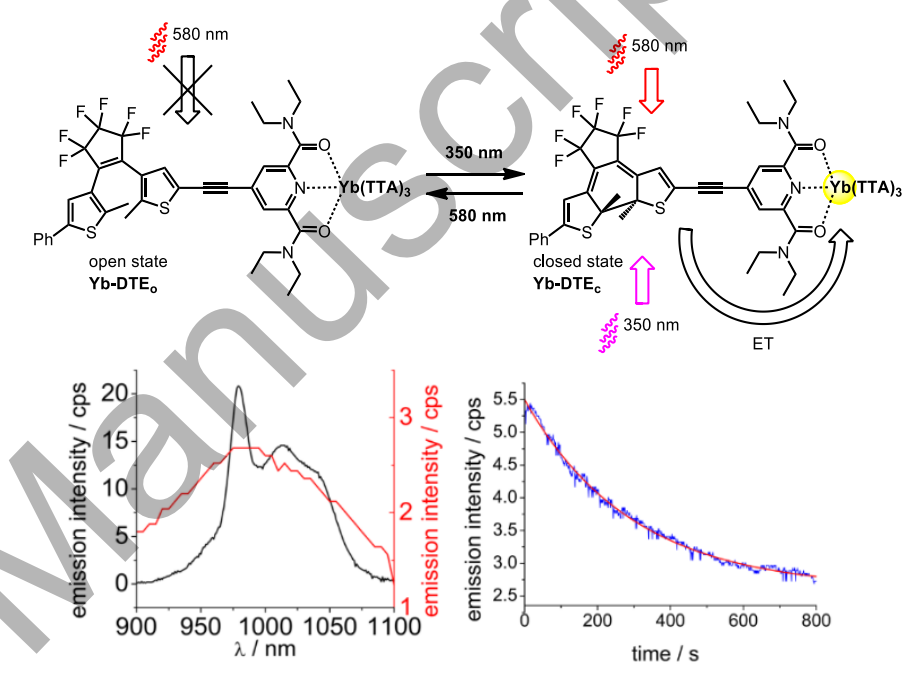

Figure 20. (up) Chemical formula of Yb-DTE in its both forms. (bottom left) Emission spectra of $\mathbf{Y b}-\mathbf{D T E}_{\mathrm{c}}$, in dichloromethane at room temperature with $\lambda_{\mathrm{ex}}=$ $350 \mathrm{~nm}$ (black) and $\lambda_{\mathrm{ex}}=580 \mathrm{~nm}$ (red). (bottom right) Evolution of the emission at $\lambda=1000 \mathrm{~nm}$ upon irradiation at $\lambda=580 \mathrm{~nm}$ leading to conversion of $\mathbf{Y b}-\mathbf{D T E}_{\mathrm{c}}$ $\left([C] \approx 1 \times 10^{-5} \mathrm{~mol} \cdot \mathrm{L}^{-1}\right.$ ) to $\mathrm{Yb}-\mathrm{DTE}_{\mathrm{o}}$ and the mono-exponential fit (red line) with $\mathrm{T}=10 \mathrm{~s} \cdot{ }^{[59 \mathrm{~d}]}$ Adapted with permission. Copyright 2016, ACS.

In order to improve the process efficiency, we designed an alternative $\mathrm{Yb}$ (III) complex based on the dimethyl-cyclen platform Medo2pa, known to provide high stability constants. The complex bears two DTE units attached to each picolinate arms in order to also rise sensitization effectiveness through the cyclized DTE chromophore (Figure 21). ${ }^{59 \mathrm{e}]}$ The complexes showed a reversible photochromism with high conversions. However, in this case, no ytterbium emission was detected upon $350 \mathrm{~nm}$ excitation at room temperature. In contrast, at $77 \mathrm{~K}$ (ethanol/methanol organic glass), with slackening of the non-radiative processes, the typical emission signal of ytterbium was detected. After closing of the DTE units, the intensity of this transition was drastically reduced and a very efficient quenching up to $90 \%$ was obtained at 1000 $\mathrm{nm}$. Importantly, we showed that the photochromic reaction proceeds at $77 \mathrm{~K}$ allowing the complex luminescence modulation at low temperature. However, the complex does not display any sensitization at $580 \mathrm{~nm}$ through the cyclized DTE units, whatever the temperature. The possibility of quenching of the emission in the closed state with a low lying triplet state would explain the overall behavior and is presently being explored. 

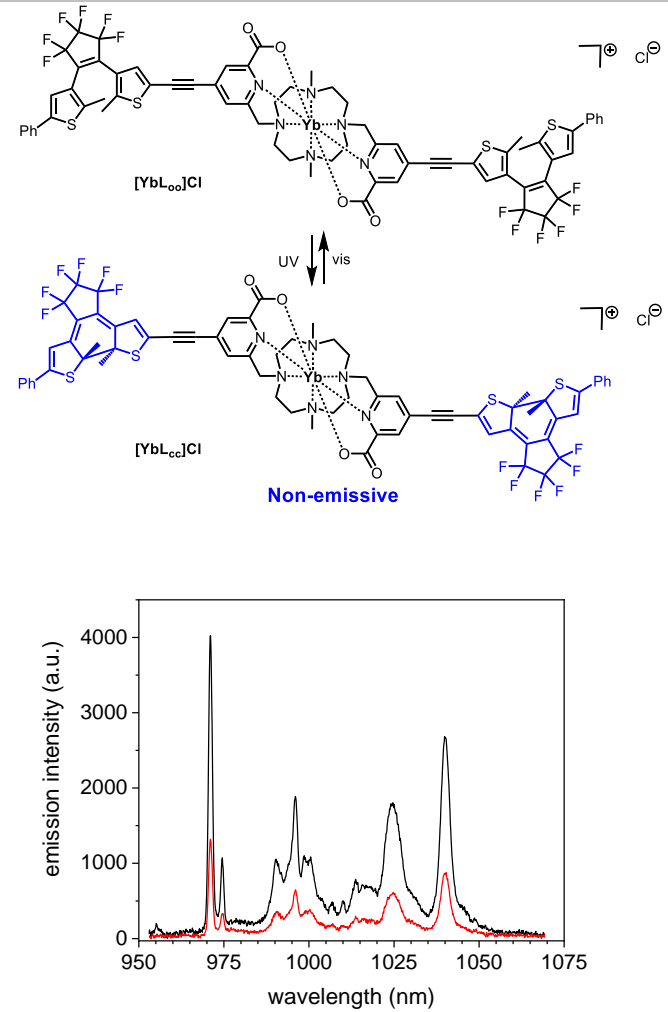

Figure 21. (up) Chemical formula of the complex in its both forms. (bottom) Emission spectra $\left(\lambda_{\mathrm{ex}}=350 \mathrm{~nm}\right)$ of [ $\left.\mathrm{L}_{o o} \mathrm{Yb}\right] \mathrm{Cl}$ (black line) and $\left[\mathrm{L}_{c c} \mathrm{Yb}\right] \mathrm{Cl}$. (red line) in ethanol : methanol (4:1) organic glass at $77 \mathrm{~K} .{ }^{[59 e]}$ Reproduced with permission. Copyright 2020, RSC.

In a further work, we accomplished the double photochemical and electrochemical control of $\mathrm{Yb}$ (III) luminescence with high contrast in both cases (Figure 22). ${ }^{[63]}$ The new system takes benefit of the photo-stimulation of three DTE units coordinated to the $\mathrm{Yb}$ (III) center by a $\beta$-diketonate moiety and of the redox switching thanks to the above mentioned carbon-rich ruthenium antenna. The later exhibit a typical MLCT transition $\left(\lambda_{\max }=450\right.$ $\mathrm{nm}$ ) that can be used to trigger ytterbium response at $\lambda_{\max }=980$ $\mathrm{nm}$. Further experiments showed (i) the vanishing (to $1.4 \%$ of initial maximum intensity) of the luminescence signal after UV treatment $(\lambda=350 \mathrm{~nm})$ and DTE closures at the PSS, and (ii) a total recovery of the emission signal up to its initial intensity after visible treatment $(\lambda=650 \mathrm{~nm})$ with reopening of the DTE photochromic components. We then established that excitation in the MLCT band offers an effective non-destructive readout of the system state. A dynamic photoswitching response could also be demonstrated: when excitation was performed at the photocyclization wavelength $(\lambda=350 \mathrm{~nm})$ and using the DTE $\beta$ diketonate ligands or the bipyridine unit as sensitizers, a fast decrease of the NIR emission was observed. Again, the hypothesis of a closed DTE triplet excited state lying at lower energy than that of the ${ }^{2} \mathrm{~F}_{5 / 2}$ excited state of the $\mathrm{Yb}$ (III) ion (10 200 $\left.\mathrm{cm}^{-1}\right)$ is the most likely. ${ }^{[1]}$ Electrochemical methods coupled to fluorescence spectroscopy was then applied to demonstrate redox switching (one electron oxidation at $E_{1}{ }^{\circ}=0.049 \mathrm{~V} v s$. $\mathrm{FeCp}_{2} / \mathrm{FeCp}_{2}{ }^{+}$). When scanning the electrode potential between $0.1 \mathrm{~V}$ an $1 \mathrm{~V}$, the changes in the emission intensity correlates with the redox event, and oxidation causes a drastic drop in the signal intensity down to $12 \%$ of its initial value, which can be nearly fully restored (93\%) upon electroreduction of the system. Note that this system was unable to promote sensitization of the $\mathrm{Eu}(\mathrm{III})$ ion, possibly because of a deactivation process provided by MLCT states of the acetylide moiety.

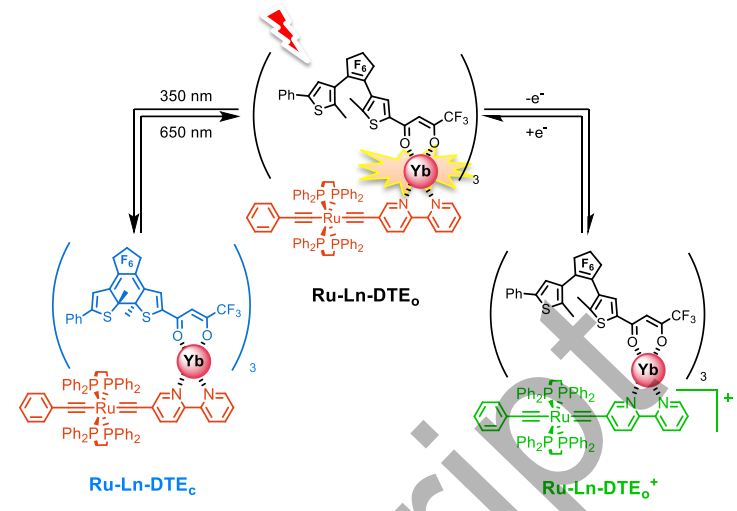

Figure 22. (up) Chemical formula of Ru-Yb-DTE in its different forms. (middle left) Initial emission spectrum of Ru-Yb-DTEo in $\mathrm{CH}_{2} \mathrm{Cl}_{2}$ (blue), after UV irradiation $\left(\lambda_{\text {irr }}=350 \mathrm{~nm}\right.$, red), and then bleaching $\left(\lambda_{\text {irr }}=650 \mathrm{~nm}\right.$, dashed) with $\lambda_{\mathrm{ex}}=450 \mathrm{~nm}$. (middle right) Emission decay upon UV irradiation. Each spectrum is recorded with a 1s time lapse. (bottom) Emission monitoring at $\lambda=1025$ ( $\lambda_{\text {ex }}$ $=450 \mathrm{~nm}$ ) upon oxidation and reduction the electrochemical cell, and
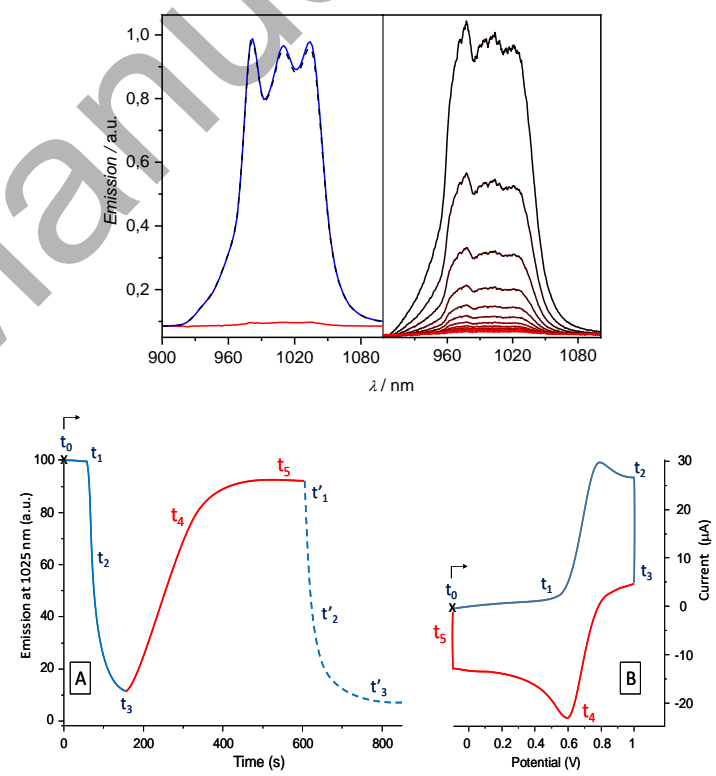

simultaneously measured current-potential curve showing oxidation and reduction of $\mathrm{Ru}-\mathrm{Yb}$-DTEo ( $\mathrm{E}^{\circ}=0.69 \mathrm{~V}$ vs. Ag wire pseudo reference). ${ }^{[63]}$ Reproduced with permission. Copyright 2019, ACS.

In light of these results, we then developed a simpler and highly stable system by mixing the same DTE entities and the lanthanide(III) ion with one phenanthroline unit (Figure 23). ${ }^{[64]}$ This new system is able to sensitize either the $\mathrm{Eu}(\mathrm{III})$ and the $\mathrm{Yb}(\mathrm{III})$ ions. It shows two ways for encryption: (i) coloration and discoloration of the photochromic entities can be used to draw (350 nm) or erase (visible light) a colorful code, and (ii) gradual vanishing and restoration of the lanthanide ion emission is activated with the identical set of stimuli. The novelty of the system comes from the versatility of the emission color with either a lanthanide ion emitting only in the visible range $(\mathrm{Eu}(\mathrm{III}))$ or in the NIR range $(\mathrm{Yb}(\mathrm{III}))$, therefore observable, or not, to the naked eye. These interesting features were perfectly maintained when the system was embedded in a polydimethylsiloxane (PDMS) polymer, opening actual opportunities for applications such as anti-counterfeiting. In particular, the $\mathrm{Yb}$ (III) system appears as a simple colorimetric system, when it is much more sophisticated in 
reality. The emission spectra of the films were comparable to those found in solution and a quenching down to $3 \%$ of the initial emission intensity was detected after 1 minute, whereas $75 \%$ quenching is attained in only 4 seconds. Also, several sequences of closing/opening cycles were achieved to demonstrate the high stability and the high reversibility of the emission signals of these systems.
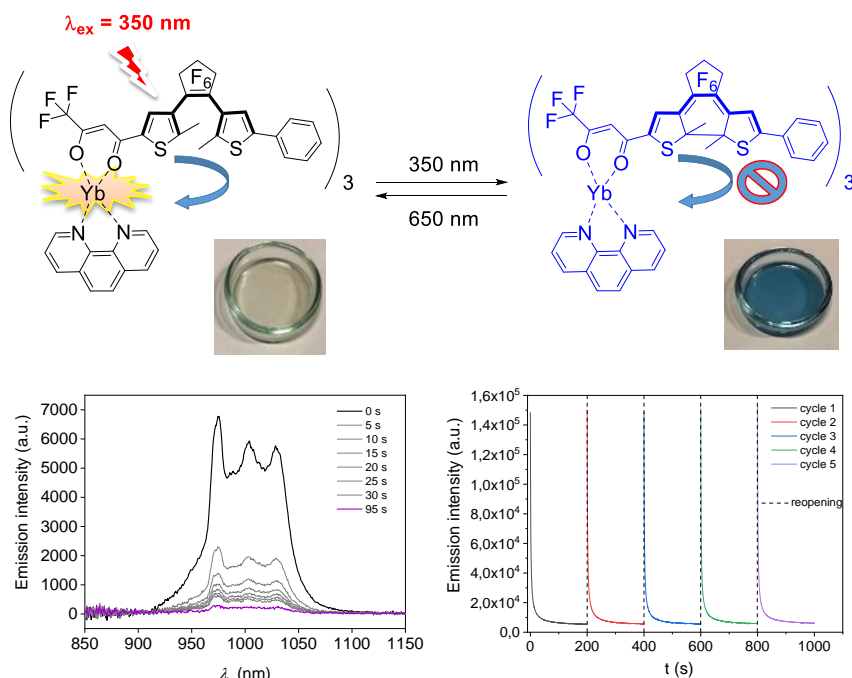

Figure 23. (up) Chemical formula of $\operatorname{Ln}(\mathrm{DTE})_{3}$ Phen $(\mathrm{Ln}=\mathrm{Eu}, \mathrm{Yb})$ and their photoisomerization process. Emission decrease (bottom left) of $\mathrm{Yb}(\mathrm{DTE})_{3} \mathrm{Phen}$ in PDMS films ( $0.2 \%$ wt.) obtained with a CCD camera with $5 \mathrm{~s}$ integration time $\left(\lambda_{\mathrm{ex}}=350 \mathrm{~nm}\right)$, (bottom right) measured at $1000 \mathrm{~nm}$ with a CCD camera with $0.2 \mathrm{~s}$ integration time upon UV excitation at $\lambda_{\mathrm{ex}}=378 \mathrm{~nm}$ (isobestic point). Total reopening was conducted with a halogen lamp with a $455 \mathrm{~nm}$ long pass filter. ${ }^{[64]}$ Reproduced with permission. Copyright 2020, Wiley.

\section{Conclusion.}

In conclusion, the studies presented in this review are clear validations of the strategy that consists in the achievement of NIR luminescence switching of $\mathrm{Ln}$ ions with various stimuli. More precisely, all these studies show that a high level of functionality may be integrated into a lanthanide molecular system permitting chemical, temperature, redox or photochemical control of NIR emission. However, the field has so far focused on the demonstration of proofs of principles. The next step towards applications will then consist in the optimization of the observed behaviors in terms of brightness of the molecular probe in its $O N$ state and of contrast between the ON and OFF states. Concerning the brightness, the recent progresses in designing complexes with high quantum yields ${ }^{[17]}$ can inspire new designs in which the sensitization in the ON state will be optimized, while the deleterious non-radiative processes are blocked. Concomitantly, thorough investigations of the involved photophysical processes are also mandatory for the development of these improved switching systems. In other words, future works may rely on transient absorption experiment to determine inter alia the nature of the ligand-excited states, the nature of the corresponding energy transfers or their kinetics. We also believe that this approach is especially relevant for the photochromic systems. Indeed, in order to take full advantage of the superiority of light as a contactless, spatially and temporally resolved stimulus in the design of further smart materials, it seems very appealing to continue to explore and take advantage of NIR emission photoswitching. To that regard, while many closed DTEs have their visible absorption around $600 \mathrm{~nm}$ and then seem more adapted to switch off Europium luminescence, we have demonstrated that their behavior is actually more versatile and can be used i) for quenching NIR emitters and ii) to control visible sensitization of NIR emitters. Thus, we strongly believe that a dark triplet state adapted i) to NIR emission quenching or ii) to sensitization of the lanthanide in the visible range could play a role in these different mechanisms, depending on their energy. We are now engaged in demonstrating such possibilities in order to tune the photochromic unit architecture and precisely adapt them to NIR emission. In a more general perspective, given the vast collection of possible metal-ligand combinations and engineering of functional ligand to improve switching features, we foresee many improvements and the developments of original systems with great potentials for lanthanide complexes in future material applications. For example, concerning anticounterfeiting applications, the design of systems with mixture/association of different ions and complexes in specific ratio that can be photochromic or not, should allow the production of markers with specific fingerprints and temporal response, including dynamic bar codes and physical unclonable functions (PUFs). ${ }^{[65]}$

\section{Acknowledgements}

We thank the Universite de Rennes 1, the CNRS, and the Agence Nationale de la Recherche (ANR) for support.

Keywords: Near-Infrared - Emission Control $\cdot$ Lanthanide Ion • - Photochrome $\cdot$ Redox

[1] (a) Molecular Switches. Wiley-VCH, Weinheim, Germany: 2011; (b) J. J. Zhang, Q. Zou,H. Tian, Adv. Mater. 2013, 25, 378-399; (c) R. Klajn, Chem. Soc Rev. 2014, 43, 148-184; (d) M. Natali,S. Giordani, Chem. Soc. Rev. 2012, 41 4010-4029; (e) M. Irie, T. Fulcaminato, K. Matsuda,S. Kobatake, Chem. Rev. 2014, 114, 12174-12277; (f) S. Erbas-Cakmak, D. A. Leigh, C. T. McTernan,A. L. Nussbaumer, Chem. Rev. 2015, 115, 10081-10206.

[2] P. Audebert,F. Miomandre, Chem. Sci. 2013, 4, 575-584.

[3] M. M. A. Mazza,F. M. Raymo, J. Mater. Chem. 2019, 7, 5333-5342.

[4] (a) Y. Zhang,F. M. Raymo, Bioconjugate Chem. 2020, 31, 1052-1062; (b) Z. Tian,A. D. Q. Li, Acc. Chem. Res. 2013, 46, 269-279; (c) T. Fukaminato, Journal of Photochemistry and Photobiology C 2011, 12, 177-208.

[5] (a) A. Zampetti, A. Minotto,F. Cacialli, Adv. Funct. Mater. 2019, 29, 1807623; (b) D. Zou, J. Zhang, Y. Cui,G. Qian, Dalton Trans. 2019, 48, 6669-6675; (c) Y. Ning, M. Zhu,J.-L. Zhang, Coord. Chem. Rev. 2019, 399, 213028; (d) J. Xu A. Gulzar, P. Yang, H. Bi, D. Yang, S. Gai, F. He, J. Lin, B. Xing,D. Jin, Coord. Chem. Rev. 2019, 381, 104-134.

[6] A. M. Smith, M. C. Mancini,S. Nie, Nat. Nanotechnol. 2009, 4, 710-711.

[7] A. T. Bui, M. Beyler, A. Grichine, A. Duperray, J.-C. Mulatier, Y. Guyot, C. Andraud, R. Tripier, S. Brasselet,O. Maury, Chem. Commun. 2017, 53, 6005 6008.

[8] S. Bonacchi, A. Cantelli, G. Battistelli, G. Guidetti, M. Calvaresi, J. Manzi, L. Gabrielli, F. Ramadori, A. Gambarin, F. Mancin,M. Montalti, Angew. Chem. Int. Ed. 2016, 55, 11064-11068.

[9] H. Lim, S. Seo, S. Pascal, Q. Bellier, S. Rigaut, C. Park, H. Shin, O. Maury C. Andraud,E. Kim, Scientific reports 2016, 6, 18867-18867.

[10] K. Jeong, S. Park, Y.-D. Lee, C.-K. Lim, J. Kim, B. H. Chung, I. C. Kwon, C. R. Park,S. Kim, Adv. Mater. 2013, 25, 5574-5580.

[11] (a) A. D'Aleo, F. Pointillart, L. Ouahab, C. Andraud,O. Maury, Coord. Chem Rev. 2012, 256, 1604-1620; (b) E. G. Moore, A. P. S. Samuel,K. N. Raymond Acc. Chem. Res. 2009, 42, 542-552; (c) J.-C. G. Bünzli, Coord. Chem. Rev. 2015, 293-294, 19-47.

[12] (a) S. V. Eliseeva,J.-C. G. Buenzli, Chem. Soc. Rev. 2010, 39, 189-227;

(b) D. Parker, R. S. Dickins, H. Puschmann, C. Crossland,J. A. K. Howard, Chem. Rev. 2002, 102, 1977-2010.

[13] T. J. Sørensen,S. Faulkner, Acc. Chem. Res. 2018, 51, 2493-2501. 
[14] F. Pointillart, B. Le Guennic, S. Golhen, O. Cador, O. Maury,L. Ouahab, Chem. Commun. 2013, 49, 615-617.

[15] N. Hamon, A. Roux, M. Beyler, J.-C. Mulatier, C. Andraud, C. Nguyen, M. Maynadier, N. Bettache, A. Duperray, A. Grichine, S. Brasselet, M. Gary-Bobo, O. Maury,R. Tripier, J. Am. Chem. Soc. 2020, 142, 10184-10197.

[16] (a) Z. Li, G. Wang, Y. Ye, B. Li, H. Li,B. Chen, Angew. Chem. Int. Ed. 2019, 58, 18025-18031; (b) O. Guillou, C. Daiguebonne, G. Calvez,K. Bernot, Acc. Chem. Res. 2016, 49, 844-856; (c) J. Wang, Y. Suffren, C. Daiguebonne, S. Freslon, K. Bernot, G. Calvez, L. Le Pollès, C. Roiland,O. Guillou, Inorg. Chem. 2019, 58, 2659-2668; (d) Z. Gao, B. Xu, T. Zhang, Z. Liu, W. Zhang, X. Sun, Y. Liu, X. Wang, Z. Wang, Y. Yan, F. Hu, X. Meng,Y. S. Zhao, Angew. Chem. Int. Ed. n/a; (e) J. Andres, R. D. Hersch, J.-E. Moser,A.-S. Chauvin, Adv. Funct. Mater. 2014, 24, 5029-5036; (f) J. M. Meruga, A. Baride, W. Cross, J. J. Kellar,P. S. May, J. Mater. Chem. 2014, 2, 2221-2227; (g) M. R. Carro-Temboury, R. Arppe, T. Vosch,T. J. Sørensen, Science Advances 2018, 4, e1701384.

[17] (a) J.-Y. Hu, Y. Ning, Y.-S. Meng, J. Zhang, Z.-Y. Wu, S. Gao,J.-L. Zhang, Chem. Sci. 2017, 8, 2702-2709; (b) C. Doffek,M. Seitz, Angew. Chem. Int. Ed. 2015, 54, 9719-9721.

[18] Q. Qi, C. Li, X. Liu, S. Jiang, Z. Xu, R. Lee, M. Zhu, B. Xu,W. Tian, J. Am. Chem. Soc. 2017, 139, 16036-16039.

[19] (a) M. C. Heffern, L. M. Matosziuk,T. J. Meade, Chem. Rev. 2014, 114, 4496-4539; (b) X. Wang, H. Chang, J. Xie, B. Zhao, B. Liu, S. Xu, W. Pei, N. Ren, L. Huang,W. Huang, Coord. Chem. Rev. 2014, 273-274, 201-212.

[20] (a) C. M. G. dos Santos, A. J. Harte, S. J. Quinn,T. Gunnlaugsson, Coord. Chem. Rev. 2008, 252, 2512-2527; (b) A. B. Aletti, D. M. Gillen,T Gunnlaugsson, Coord. Chem. Rev. 2018, 354, 98-120; (c) S. Shuvaev, M. Starck,D. Parker, Chem. Eur. J. 2017, 23, 9974-9989.

[21] E. Pershagen,K. E. Borbas, Coord. Chem. Rev. 2014, 273-274, 30-46.

[22] L. K. Truman, S. Comby,T. Gunnlaugsson, Angew. Chem. Int. Ed. 2012, 51, 9624-9627.

[23] J. D. Routledge, M. W. Jones, S. Faulkner,M. Tropiano, Inorg. Chem. 2015, 54, 3337-3345.

[24] Y. Ning, S. Cheng, J.-X. Wang, Y.-W. Liu, W. Feng, F. Li,J.-L. Zhang, Chem Sci. 2019, 10, 4227-4235.

[25] (a) T. Liu, A. Nonat, M. Beyler, M. Regueiro-Figueroa, K. Nchimi Nono, O. Jeannin, F. Camerel, F. Debaene, S. Cianférani-Sanglier, R. Tripier, C. PlatasIglesias, L. J. Charbonnière, Angew. Chem. Int. Ed. 2014, 53, 7259-7263; (b) A. Nonat, T. Liu, O. Jeannin, F. Camerel,L. J. Charbonnière, Chem. Eur. J. 2018, 24, 3784-3792.

[26] O. A. Blackburn, A. M. Kenwright, A. R. Jupp, J. M. Goicoechea, P. D. Beer,S. Faulkner, Chem. Eur. J. 2016, 22, 8929-8936.

[27] G. Bao, S. Zha, Z. Liu, Y.-H. Fung, C.-F. Chan, H. Li, P.-H. Chu, D. Jin, P. A. Tanner,K.-L. Wong, Inorg. Chem. 2018, 57, 120-128.

[28] T. Zhang, C.-F. Chan, R. Lan, W.-K. Wong,K.-L. Wong, Chem. Eur. J. 2014, 20, 970-973.

[29] A. Watkis, R. Hueting, T. J. Sørensen, M. Tropiano,S. Faulkner, Chem. Commun. 2015, 51, 15633-15636.

[30] Y. Ning, X.-S. Ke, J.-Y. Hu, Y.-W. Liu, F. Ma, H.-L. Sun,J.-L. J. I. c. Zhang, 2017, 56, 1897-1905.

[31] W.-S. Lo, H. Li, G.-L. Law, W.-T. Wong,K.-L. Wong, J. Lumin. 2016, 169, $549-552$.

[32] X. S. Ke, B. Y. Yang, X. Cheng, S. L. F. Chan,J. L. J. Zhang, Chemistry-A European Journal 2014, 20, 4324-4333.

[33] K. Driesen, D. Moors, J. Beeckman, K. Neyts, C. Görller-Walrand,K. Binnemans, J. Lumin. 2007, 127,611-615.

[34] L. J. Yu,M. M. Labes, Appl. Phys. Lett. 1977, 31, 719-720.

[35] M. Deng, N. D. Schley, G. Ung, Inorg. Chem. 2018, 57, 15399-15405.

[36] J. H. S. K. Monteiro, N. R. Fetto, M. J. Tucker,A. de Bettencourt-Dias, Inorg. Chem. 2020, 59, 3193-3199.

[37] S. S. Sun, Z. Wang, X. W. Wu, J. H. Zhang, C. J. Li, S. Y. Yin, L. Chen, M. Pan,C. Y. Su, Chem. Eur. J. 2018, 24, 10091-10098.

[38] G. Kucsko, P. C. Maurer, N. Y. Yao, M. Kubo, H. J. Noh, P. K. Lo, H. Park,M. D. Lukin, Nature 2013, 500, 54-8.

[39] C. D. Brites, P. P. Lima, N. J. Silva, A. Millan, V. S. Amaral, F. Palacio, L. D. Carlos, Nanoscale 2012, 4, 4799-829.

[40] B. R. Anderson, R. Gunawidjaja,H. Eilers, J. Lumin. 2018, 204, 341-348. [41] (a) Y. Hasegawa, Y. Kitagawa, Journal of Materials Chemistry C 2019, 7, 7494-7511; (b) C. D. S. Brites, P. P. Lima, N. J. O. Silva, A. Millan, V. S. Amaral, F. Palacio,L. D. Carlos, New J Chem 2011, 35, 1177-1183.

[42] G. Brunet, R. Marin, M. J. Monk, U. Resch-Genger, D. A. Galico, F. A. Sigoli, E. A. Suturina, E. Hemmer,M. Murugesu, Chem. Sci. 2019, 10, 67996808.

[43] (a) Y. Ning, X. S. Ke, J. Y. Hu, Y. W. Liu, F. Ma, H. L. Sun,J. L. Zhang, Inorg. Chem. 2017, 56, 1897-1905; (b) Y. Ning, Y. W. Liu, Y. S. Meng,J. L. Zhang, Inorg. Chem. 2018, 57, 1332-1341.
[44] X. Zhou, Y. Wang, H. Wang, L. Xiang, Y. Yan, L. Li, G. Xiang, Y. Li, S. Jiang, X. Tang, X. Zhou, Sensing and Bio-Sensing Research 2020, 29, 100345. [45] M. Tang, Y. Huang, Y. Wang, L. Fu, Dalton Trans 2015, 44, 7449-57.

[46] D. Zhao, X. Han, S. Wang, J. Liu, Y. Lu,C. Li, Chem. Eur. J. 2020, 26, 3145-3151.

[47] M. Asano-Someda,Y. Kaizu, Journal of Photochemistry and Photobiology A: Chemistry 2001, 139, 161-165.

[48] J. Wang, J. J. Zakrzewski, M. Heczko, M. Zychowicz, K. Nakagawa, K. Nakabayashi, B. Sieklucka, S. Chorazy,S. I. Ohkoshi, J. Am. Chem. Soc. 2020, 142, 3970-3979.

[49] (a) M. Yano, K. Matsuhira, M. Tatsumi, Y. Kashiwagi, M. Nakamoto, M. Oyama, K. Ohkubo, S. Fukuzumi, H. Misaki,H. Tsukube, Chem. Commun. 2012, 48, 4082-4084; (b) J. Chen, Z. Xie, L. Meng, Z. Hu, X. Kuang, Y. Xie,C.-Z. Lu, Inorg. Chem. 2020, 59, 6963-6977; (c) M. Tropiano, N. L. Kilah, M. Morten, H. Rahman, J. J. Davis, P. D. Beer,S. Faulkner, J. Am. Chem. Soc. 2011, 133 11847-11849; (d) J. K. Molloy, O. Jarjayes, C. Philouze, L. Fedele, D. Imbert,F. Thomas, Chem. Commun. 2017, 53, 605-608; (e) J. K. Molloy, L. Fedele, O. Jarjayes, C. Philouze, D. Imbert,F. Thomas, Inorg. Chim. Acta 2018, 483, 609617.

[50] T. Sato,M. Higuchi, Chem. Commun. 2013, 49, 5256-5258.

[51] (a) Q. Li,V. W.-W. Yam, Angew. Chem. Int. Ed. 2007, 46, 3486-3489; (b) G. Phaomei, R. S. Ningthoujam, W. R. Singh, R. S. Loitongbam, N. S. Singh, A. Rath, R. R. Juluri,R. K. Vatsa, Dalton Trans. 2011, 40, 11571-11580; (c) M. Kitsuda,S. Fujihara, J. Phys. Chem. C 2011, 115, 8808-8815.

[52] (a) K. Kanazawa, K. Nakamura,N. Kobayashi, J. Mater. Chem. 2015, 3 7135-7142; (b) J. Lehr, M. Tropiano, P. D. Beer, S. Faulkner,J. J. Davis, Chem. Commun. 2015, 51, 6515-6517.

[53] Y. Hasegawa, N. Sato, Y. Hirai, T. Nakanishi, Y. Kitagawa, A. Kobayashi, M. Kato, T. Seki, H. Ito,K. Fushimi, The Journal of Physical Chemistry A 2015, $119,4825-4833$.

[54] E. Di Piazza, L. Norel, K. Costuas, A. Bourdolle, O. Maury,S. Rigaut, J. Am. Chem. Soc. 2011, 133, 6174-6176.

[55] L. Norel, E. Di Piazza, M. Feng, A. Vacher, X. Y. He, T. Roisnel, O. Maury,S. Rigaut, Organometallics 2014, 33, 4824-4835.

[56] J. K. Molloy, C. Philouze, L. Fedele, D. Imbert, O. Jarjayes,F. Thomas, Dalton Trans. 2018, 47, 10742-10751.

[57] B. Lefeuvre, J. Flores Gonzalez, F. Gendron, V. Dorcet, F. Riobé, V. Cherkasov, O. Maury, B. Le Guennic, O. Cador, V. Kuropatov,F. Pointillart, Molecules 2020, 25, 492.

[58] D. Canevet, M. Sallé, G. Zhang, D. Zhang,D. Zhu, Chem. Commun. 2009, 2245-2269.

[59] (a) T. Nakagawa, Y. Hasegawa,T. Kawai, J. Phys. Chem. A 2008, 112, 5096-5103; (b) T. Nakagawa, Y. Hasegawa,T. Kawai, Chem. Commun. 2009, 5630-5632; (c) Y. Hasegawa, T. Nakagawa,T. Kawai, Coord. Chem. Rev. 2010, 254, 2643-2651; (d) X. He, L. Norel, Y.-M. Hervault, R. Métivier, A. D'Aléo, O. Maury,S. Rigaut, Inorg. Chem. 2016, 55, 12635-12643; (e) H. Al Sabea, N. Hamon, O. Galangau, L. Norel, O. Maury, F. Riobé, R. Tripier,S. Rigaut, Inorg. Chem. Front. 2020, 7, 2979-2989.

[60] (a) H.-B. Cheng, H.-Y. Zhang,Y. Liu, J. Am. Chem. Soc. 2013, 135, 1019010193; (b) H.-B. Cheng, G.-F. Hu, Z.-H. Zhang, L. Gao, X. Gao,H.-C. Wu, Inorg. Chem. 2016, 55, 7962-7968; (c) J. F. Mei, Z. P. Lv, J. C. Lai, X. Y. Jia, C. H. Li, J. L. Zuo, X. Z. You, Dalton Trans. 2016, 45, 5451-5454; (d) M. Koji, N. Yoshio,K. Keiichi, Bull. Chem. Soc. Jpn. 2009, 82, 472-474; (e) F. Hu, X. Li, Y. Leng, Y. Zhang, M. Zhou,Y. Ou, Inorg. Chim. Acta 2017, 458, 45-49; (f) N. Wang, J. Wang, D. Zhao, S. K. Mellerup, T. Peng, H. Wang,S. Wang, Inorg. Chem. 2018, 57, 10040-10049; (g) Y. Zhou, H.-Y. Zhang, Z.-Y. Zhang,Y. Liu, J. Am. Chem. Soc. 2017, 139, 7168-7171.

[61] (a) W. Yang, H.-R. Tian, J.-P. Li, Y.-F. Hui, X. He, J. Li, S. Dang, Z. Xie,Z. M. Sun, Chem. Eur. J. 2016, 22, 15451-15457; (b) J.-K. Sun, L.-X. Cai, Y.-J. Chen, Z.-H. Li,J. Zhang, Chem. Commun. 2011, 47, 6870-6872; (c) H.-Y. Li, H. Xu, S.-Q. Zang,T. C. W. Mak, Chem. Commun. 2016, 52, 525-528.

[62] Z. Wang, Y. Ma, R. Zhang, A. Peng, Q. Liao, Z. Cao, H. Fu,J. Yao, Adv. Mater. 2009, 21, 1737-1741.

[63] H. Al Sabea, L. Norel, O. Galangau, H. Hijazi, R. Métivier, T. Roisnel, O. Maury, C. Bucher, F. Riobé,S. Rigaut, J. Am. Chem. Soc. 2019, 141, 20026 20030.

[64] H. Al Sabea, L. Norel, O. Galangau, T. Roisnel, O. Maury, F. Riobé,S. Rigaut, Adv. Funct. Mater. 2020, 2002943.

[65] R. Arppe,T. J. Sørensen, Nature Reviews Chemistry 2017, 1, 0031. 


\section{Entry for the Table of Contents}

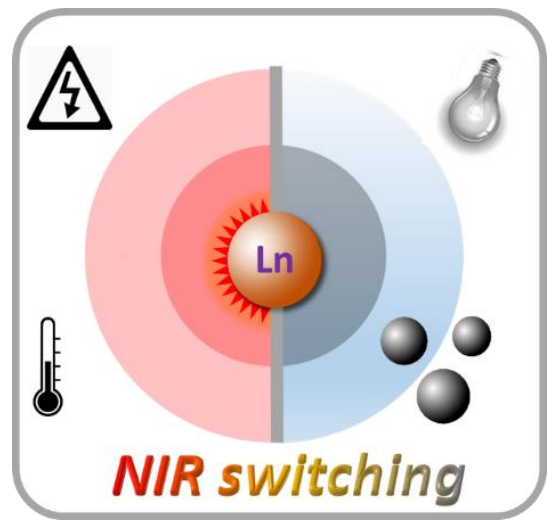

Switchable Near InfraRed (NIR) emitters are of major interest since they are compatible with in vivo imaging and have potential for advanced materials. In this review, we selected representative example of switchable lanthanide NIR emitters based on relevant stimuli, such as a chemical, environmental, thermal, electrochemical and photochemical inputs. Lanthanides are of particular interest for their narrow, sharp and intense emission lines.

Institute and/or researcher Twitter usernames: ((optional)) 
[1] (a) Molecular Switches. Wiley-VCH, Weinheim, Germany: 2011; (b) J. J. Zhang, Q. Zou,H. Tian, Adv. Mater. 2013, 25, 378-399; (c) R. Klajn, Chem. Soc. Rev. 2014, 43, 148-184; (d) M. Natali,S. Giordani, Chem. Soc. Rev. 2012, 41, 4010-4029; (e) M. Irie, T. Fulcaminato, K. Matsuda,S. Kobatake, Chem. Rev. 2014, 114, 12174-12277; (f) S. Erbas-Cakmak, D. A. Leigh, C. T. McTernan,A. L. Nussbaumer, Chem. Rev. 2015, 115, 10081-10206.

[2] P. Audebert,F. Miomandre, Chem. Sci. 2013, 4, 575-584.

[3] M. M. A. Mazza,F. M. Raymo, J. Mater. Chem. 2019, 7, 5333-5342.

[4] (a) Y. Zhang,F. M. Raymo, Bioconjugate Chem. 2020, 31, 1052-1062; (b) Z. Tian,A. D. Q. Li, Acc. Chem. Res. 2013, 46, 269-279; (c) T. Fukaminato, Journal of Photochemistry and Photobiology C 2011, 12, 177-208.

[5] (a) A. Zampetti, A. Minotto,F. Cacialli, Adv. Funct. Mater. 2019, 29, 1807623; (b) D. Zou, J. Zhang, Y. Cui,G. Qian, Dalton Trans. 2019, 48, 6669-6675; (c) Y. Ning, M. Zhu,J.-L. Zhang, Coord. Chem. Rev. 2019, 399, 213028; (d) J. Xu, A. Gulzar, P. Yang, H. Bi, D. Yang, S. Gai, F. He, J. Lin, B. Xing, D. Jin, Coord. Chem. Rev. 2019, 381, 104-134.

[6] A. M. Smith, M. C. Mancini,S. Nie, Nat. Nanotechnol. 2009, 4, 710-711.

[7] A. T. Bui, M. Beyler, A. Grichine, A. Duperray, J.-C. Mulatier, Y. Guyot, C. Andraud, R. Tripier, S. Brasselet,O. Maury, Chem. Commun. 2017, 53, 6005-6008.

[8] S. Bonacchi, A. Cantelli, G. Battistelli, G. Guidetti, M. Calvaresi, J. Manzi, L. Gabrielli, F. Ramadori, A. Gambarin, F. Mancin,M. Montalti, Angew. Chem. Int. Ed. 2016, 55, 11064-11068.

[9] H. Lim, S. Seo, S. Pascal, Q. Bellier, S. Rigaut, C. Park, H. Shin, O. Maury, C. Andraud,E. Kim, Scientific reports 2016, 6, $18867-18867$. [10] K. Jeong, S. Park, Y.-D. Lee, C.-K. Lim, J. Kim, B. H. Chung, I. C. Kwon, C. R. Park,S. Kim, Adv. Mater. 2013, 25, 5574-5580.

[11] (a) A. D'Aleo, F. Pointillart, L. Ouahab, C. Andraud,O. Maury, Coord. Chem. Rev. 2012, 256, 1604-1620; (b) E. G. Moore, A. P. S. Samuel,K. N. Raymond, Acc. Chem. Res. 2009, 42, 542-552; (c) J.-C. G. Bünzli, Coord. Chem. Rev. 2015, 293-294, $19-47$.

[12] (a) S. V. Eliseeva,J.-C. G. Buenzli, Chem. Soc. Rev. 2010, 39, 189-227; (b) D. Parker, R. S. Dickins, H. Puschmann, C. Crossland,J. A. K. Howard, Chem. Rev. 2002, 102, 1977-2010.

[13] T. J. Sørensen,S. Faulkner, Acc. Chem. Res. 2018, 51, 2493-2501.

[14] F. Pointillart, B. Le Guennic, S. Golhen, O. Cador, O. Maury,L. Ouahab, Chem. Commun. 2013, 49, 615-617.

[15] N. Hamon, A. Roux, M. Beyler, J.-C. Mulatier, C. Andraud, C. Nguyen, M. Maynadier, N. Bettache, A. Duperray, A. Grichine, S. Brasselet, M. Gary-Bobo, O. Maury,R. Tripier, J. Am. Chem. Soc. 2020, 142, 10184-10197.

[16] (a) Z. Li, G. Wang, Y. Ye, B. Li, H. Li,B. Chen, Angew. Chem. Int. Ed. 2019, 58, 18025-18031; (b) O. Guillou, C. Daiguebonne, G. Calvez,K. Bernot, Acc. Chem. Res. 2016, 49, 844-856; (c) J. Wang, Y. Suffren, C. Daiguebonne, S. Freslon, K. Bernot, G. Calvez, L. Le Pollès, C. Roiland, O. Guillou, Inorg. Chem. 2019, 58, 2659-2668; (d) Z. Gao, B. Xu, T. Zhang, Z. Liu, W. Zhang, X. Sun, Y. Liu, X. Wang, Z. Wang, Y. Yan, F. Hu, X. Meng,Y. S. Zhao, Angew. Chem. Int. Ed. n/a; (e) J. Andres, R. D. Hersch, J.-E. Moser,A.-S. Chauvin, Adv. Funct. Mater. 2014, 24, 5029-5036; (f) J. M. Meruga, A. Baride, W. Cross, J. J. Kellar,P. S. May, J. Mater. Chem. 2014, 2, 2221-2227; (g) M. R. Carro-Temboury, R. Arppe, T. Vosch,T. J. Sørensen, Science Advances 2018, 4, e1701384.

[17] (a) J.-Y. Hu, Y. Ning, Y.-S. Meng, J. Zhang, Z.-Y. Wu, S. Gao,J.-L. Zhang, Chem. Sci. 2017, 8, 2702-2709; (b) C. Doffek,M. Seitz, Angew. Chem. Int. Ed. 2015, 54, 9719-9721.

[18] Q. Qi, C. Li, X. Liu, S. Jiang, Z. Xu, R. Lee, M. Zhu, B. Xu,W. Tian, J. Am. Chem. Soc. 2017, 139, 16036-16039.

[19] (a) M. C. Heffern, L. M. Matosziuk,T. J. Meade, Chem. Rev. 2014, 114, 4496-4539; (b) X. Wang, H. Chang, J. Xie, B. Zhao, B. Liu, S. Xu, W. Pei, N. Ren, L. Huang,W. Huang, Coord. Chem. Rev. 2014, 273-274, 201-212.

[20] (a) C. M. G. dos Santos, A. J. Harte, S. J. Quinn,T. Gunnlaugsson, Coord. Chem. Rev. 2008, 252, 2512-2527; (b) A. B. Aletti, D. M. Gillen,T. Gunnlaugsson, Coord. Chem. Rev. 2018, 354, 98-120; (c) S. Shuvaev, M. Starck,D. Parker, Chem. Eur. J. 2017, 23, 9974-9989.

[21] E. Pershagen,K. E. Borbas, Coord. Chem. Rev. 2014, 273-274, 30-46.

[22] L. K. Truman, S. Comby,T. Gunnlaugsson, Angew. Chem. Int. Ed. 2012, 51, 9624-9627.

[23] J. D. Routledge, M. W. Jones, S. Faulkner,M. Tropiano, Inorg. Chem. 2015, 54, 3337-3345.

[24] Y. Ning, S. Cheng, J.-X. Wang, Y.-W. Liu, W. Feng, F. Li,J.-L. Zhang, Chem. Sci. 2019, 10, 4227-4235

[25] (a) T. Liu, A. Nonat, M. Beyler, M. Regueiro-Figueroa, K. Nchimi Nono, O. Jeannin, F. Camerel, F. Debaene, S. Cianférani-Sanglier, R. Tripier, C. Platas-Iglesias, L. J. Charbonnière, Angew. Chem. Int. Ed. 2014, 53, 7259-7263; (b) A. Nonat, T. Liu, O. Jeannin, F. Camerel,L. J. Charbonnière, Chem. Eur. J. 2018, 24, 3784-3792.

[26] O. A. Blackburn, A. M. Kenwright, A. R. Jupp, J. M. Goicoechea, P. D. Beer,S. Faulkner, Chem. Eur. J. 2016, 22, $8929-8936$.

[27] G. Bao, S. Zha, Z. Liu, Y.-H. Fung, C.-F. Chan, H. Li, P.-H. Chu, D. Jin, P. A. Tanner,K.-L. Wong, Inorg. Chem. 2018, 57, $120-128$.

[28] T. Zhang, C.-F. Chan, R. Lan, W.-K. Wong,K.-L. Wong, Chem. Eur. J. 2014, 20, 970-973.

[29] A. Watkis, R. Hueting, T. J. Sørensen, M. Tropiano,S. Faulkner, Chem. Commun. 2015, 51, 15633-15636.

[30] Y. Ning, X.-S. Ke, J.-Y. Hu, Y.-W. Liu, F. Ma, H.-L. Sun,J.-L. J. I. c. Zhang, 2017, 56, 1897-1905.

[31] W.-S. Lo, H. Li, G.-L. Law, W.-T. Wong,K.-L. Wong, J. Lumin. 2016, 169, 549-552.

[32] X. S. Ke, B. Y. Yang, X. Cheng, S. L. F. Chan,J. L. J. Zhang, Chemistry-A European Journal 2014, 20, 4324-4333.

[33] K. Driesen, D. Moors, J. Beeckman, K. Neyts, C. Görller-Walrand,K. Binnemans, J. Lumin. 2007, 127, 611-615.

[34] L. J. Yu,M. M. Labes, Appl. Phys. Lett. 1977, 31, 719-720.

[35] M. Deng, N. D. Schley, G. Ung, Inorg. Chem. 2018, 57, 15399-15405.

[36] J. H. S. K. Monteiro, N. R. Fetto, M. J. Tucker,A. de Bettencourt-Dias, Inorg. Chem. 2020, 59, 3193-3199.

[37] S. S. Sun, Z. Wang, X. W. Wu, J. H. Zhang, C. J. Li, S. Y. Yin, L. Chen, M. Pan, C. Y. Su, Chem. Eur. J. 2018, 24, $10091-10098$.

[38] G. Kucsko, P. C. Maurer, N. Y. Yao, M. Kubo, H. J. Noh, P. K. Lo, H. Park,M. D. Lukin, Nature 2013, 500, 54-8.

[39] C. D. Brites, P. P. Lima, N. J. Silva, A. Millan, V. S. Amaral, F. Palacio,L. D. Carlos, Nanoscale 2012, 4, 4799-829.

[40] B. R. Anderson, R. Gunawidjaja,H. Eilers, J. Lumin. 2018, 204, 341-348.

[41] (a) Y. Hasegawa,Y. Kitagawa, Journal of Materials Chemistry C 2019, 7, 7494-7511; (b) C. D. S. Brites, P. P. Lima, N. J. O. Silva, A. Millan, V. S. Amaral, F. Palacio,L. D. Carlos, New J Chem 2011, 35, 1177-1183.

[42] G. Brunet, R. Marin, M. J. Monk, U. Resch-Genger, D. A. Galico, F. A. Sigoli, E. A. Suturina, E. Hemmer,M. Murugesu, Chem. Sci. 2019, 10, 6799-6808.

[43] (a) Y. Ning, X. S. Ke, J. Y. Hu, Y. W. Liu, F. Ma, H. L. Sun,J. L. Zhang, Inorg. Chem. 2017, 56, 1897-1905; (b) Y. Ning, Y. W. Liu, Y. S. Meng,J. L. Zhang, Inorg. Chem. 2018, 57, 1332-1341.

[44] X. Zhou, Y. Wang, H. Wang, L. Xiang, Y. Yan, L. Li, G. Xiang, Y. Li, S. Jiang, X. Tang, X. Zhou, Sensing and Bio-Sensing Research 2020, 29, 100345.

[45] M. Tang, Y. Huang, Y. Wang,L. Fu, Dalton Trans 2015, 44, 7449-57.

[46] D. Zhao, X. Han, S. Wang, J. Liu, Y. Lu,C. Li, Chem. Eur. J. 2020, 26, 3145-3151.

[47] M. Asano-Someda,Y. Kaizu, Journal of Photochemistry and Photobiology A: Chemistry 2001, 139, 161-165.

[48] J. Wang, J. J. Zakrzewski, M. Heczko, M. Zychowicz, K. Nakagawa, K. Nakabayashi, B. Sieklucka, S. Chorazy,S. I. Ohkoshi, J. Am. Chem. Soc. 2020, 142, 3970-3979. 
[49] (a) M. Yano, K. Matsuhira, M. Tatsumi, Y. Kashiwagi, M. Nakamoto, M. Oyama, K. Ohkubo, S. Fukuzumi, H. Misaki,H. Tsukube, Chem. Commun. 2012, 48, 4082-4084; (b) J. Chen, Z. Xie, L. Meng, Z. Hu, X. Kuang, Y. Xie,C.-Z. Lu, Inorg. Chem. 2020, 59, 6963-6977; (c) M. Tropiano, N. L. Kilah, M. Morten, H. Rahman, J. J. Davis, P. D. Beer,S. Faulkner, J. Am. Chem. Soc. 2011, 133, 11847-11849; (d) J. K. Molloy, O. Jarjayes, C. Philouze, L. Fedele, D. Imbert,F. Thomas, Chem. Commun. 2017, 53, 605-608; (e) J. K. Molloy, L. Fedele, O. Jarjayes, C. Philouze, D. Imbert,F. Thomas, Inorg. Chim. Acta 2018, 483, 609-617.

[50] T. Sato,M. Higuchi, Chem. Commun. 2013, 49, 5256-5258.

[51] (a) Q. Li,V. W.-W. Yam, Angew. Chem. Int. Ed. 2007, 46, 3486-3489; (b) G. Phaomei, R. S. Ningthoujam, W. R. Singh, R. S. Loitongbam, N. S. Singh, A. Rath, R. R. Juluri,R. K. Vatsa, Dalton Trans. 2011, 40, 11571-11580; (c) M. Kitsuda,S. Fujihara, J. Phys. Chem. C 2011, 115, 8808-8815.

[52] (a) K. Kanazawa, K. Nakamura,N. Kobayashi, J. Mater. Chem. 2015, 3, 7135-7142; (b) J. Lehr, M. Tropiano, P. D. Beer, S. Faulkner,J. J. Davis, Chem. Commun. 2015, 51, 6515-6517.

[53] Y. Hasegawa, N. Sato, Y. Hirai, T. Nakanishi, Y. Kitagawa, A. Kobayashi, M. Kato, T. Seki, H. Ito,K. Fushimi, The Journal of Physical Chemistry A 2015, 119, 4825-4833.

[54] E. Di Piazza, L. Norel, K. Costuas, A. Bourdolle, O. Maury,S. Rigaut, J. Am. Chem. Soc. 2011, 133, 6174-6176.

[55] L. Norel, E. Di Piazza, M. Feng, A. Vacher, X. Y. He, T. Roisnel, O. Maury, S. Rigaut, Organometallics 2014, 33, 4824-4835

[56] J. K. Molloy, C. Philouze, L. Fedele, D. Imbert, O. Jarjayes,F. Thomas, Dalton Trans. 2018, 47, 10742-10751.

[57] B. Lefeuvre, J. Flores Gonzalez, F. Gendron, V. Dorcet, F. Riobé, V. Cherkasov, O. Maury, B. Le Guennic, O. Cador, V. Kuropatov,F. Pointillart, Molecules 2020, 25, 492.

[58] D. Canevet, M. Sallé, G. Zhang, D. Zhang,D. Zhu, Chem. Commun. 2009, 2245-2269.

[59] (a) T. Nakagawa, Y. Hasegawa,T. Kawai, J. Phys. Chem. A 2008, 112, 5096-5103; (b) T. Nakagawa, Y. Hasegawa,T. Kawai, Chem. Commun. 2009, 5630-5632; (c) Y. Hasegawa, T. Nakagawa,T. Kawai, Coord. Chem. Rev. 2010, 254, 2643-2651; (d) X. He, L. Norel, Y.-M. Hervault, R. Métivier, A. D’Aléo, O. Maury,S. Rigaut, Inorg. Chem. 2016, 55, 12635-12643; (e) H. Al Sabea, N. Hamon, O. Galangau, L. Norel, O. Maury, F. Riobé, R. Tripier,S. Rigaut, Inorg. Chem. Front. 2020, 7, 2979-2989.

[60] (a) H.-B. Cheng, H.-Y. Zhang,Y. Liu, J. Am. Chem. Soc. 2013, 135, 10190-10193; (b) H.-B. Cheng, G.-F. Hu, Z.-H. Zhang, L. Gao, X. Gao,H.-C. Wu, Inorg. Chem. 2016, 55, 7962-7968; (c) J. F. Mei, Z. P. Lv, J. C. Lai, X. Y. Jia, C. H. Li, J. L. Zuo, X. Z. You, Dalton Trans. 2016, 45, 5451-5454; (d) M. Koji, N. Yoshio,K. Keiichi, Bull. Chem. Soc. Jpn. 2009, 82, 472-474; (e) F. Hu, X. Li, Y. Leng, Y. Zhang, M. Zhou, Y. Ou, Inorg. Chim. Acta 2017, 458, 45-49; (f) N. Wang, J. Wang, D. Zhao, S. K. Mellerup, T. Peng, H. Wang,S. Wang, Inorg. Chem. 2018, 57, 10040-10049; (g) Y. Zhou, H.-Y. Zhang, Z.-Y. Zhang,Y. Liu, J. Am. Chem. Soc. 2017, 139, 7168-7171.

[61] (a) W. Yang, H.-R. Tian, J.-P. Li, Y.-F. Hui, X. He, J. Li, S. Dang, Z. Xie,Z.-M. Sun, Chem. Eur. J. 2016, 22, 15451-15457; (b) J.-K. Sun, L.-X. Cai, Y.-J. Chen, Z.-H. Li,J. Zhang, Chem. Commun. 2011, 47, 6870-6872; (c) H.-Y. Li, H. Xu, S.-Q. Zang, T. C. W. Mak, Chem. Commun. 2016, 52, 525-528.

[62] Z. Wang, Y. Ma, R. Zhang, A. Peng, Q. Liao, Z. Cao, H. Fu,J. Yao, Adv. Mater. 2009, 21, 1737-1741.

[63] H. Al Sabea, L. Norel, O. Galangau, H. Hijazi, R. Métivier, T. Roisnel, O. Maury, C. Bucher, F. Riobé,S. Rigaut, J. Am. Chem. Soc. 2019, 141, 20026-20030.

[64] H. Al Sabea, L. Norel, O. Galangau, T. Roisnel, O. Maury, F. Riobé,S. Rigaut, Adv. Funct. Mater. 2020, 2002943.

[65] R. Arppe,T. J. Sørensen, Nature Reviews Chemistry 2017, 1, 0031. 